\title{
Observational constraints on entrainment and the entrainment interface layer in stratocumulus
}

\author{
J. K. Carman ${ }^{1}$, D. L. Rossiter ${ }^{1}$, D. Khelif ${ }^{2}$, H. H. Jonsson ${ }^{3}$, I. C. Faloona ${ }^{4}$, and P. Y. Chuang ${ }^{1}$ \\ ${ }^{1}$ Earth and Planetary Sciences, University of California Santa Cruz, Santa Cruz, CA, USA \\ ${ }^{2}$ Mechanical and Aerospace Engineering, University of California Irvine, Irvine, CA, USA \\ ${ }^{3}$ Center for Interdisciplinary Remotely-Piloted Aircraft Studies, Naval Postgraduate School, Monterey, CA, USA \\ ${ }^{4}$ Department of Land, Air and Water Resources, University of California Davis, Davis, CA, USA
}

Correspondence to: P. Y. Chuang (pchuang@ucsc.edu)

Received: 30 November 2011 - Published in Atmos. Chem. Phys. Discuss.: 10 January 2012

Revised: 2 May 2012 - Accepted: 29 October 2012 - Published: 23 November 2012

\begin{abstract}
Aircraft sampling of the stratocumulus-topped boundary layer (STBL) during the Physics of Stratocumulus Top (POST) experiment was primarily achieved using sawtooth flight patterns, during which the atmospheric layer $100 \mathrm{~m}$ above and below cloud top was sampled at a frequency of once every $2 \mathrm{~min}$. The large data set that resulted from each of the 16 flights document the complex structure and variability of this interfacial region in a variety of conditions. In this study, we first describe some properties of the entrainment interface layer (EIL), where strong gradients in turbulent kinetic energy (TKE), potential temperature and moisture can be found. We find that defining the EIL by the first two properties tends to yield similar results, but that moisture can be a misleading tracer of the EIL. These results are consistent with studies using large-eddy simulations. We next utilize the POST data to shed light on and constrain processes relevant to entrainment, a key process in the evolution of the STBL that to-date is not well-represented even by high resolution models. We define "entrainment efficiency" as the ratio of the TKE consumed by entrainment to that generated within the STBL (primarily by cloud-top cooling). We find values for the entrainment efficiency that vary by 1.5 orders of magnitude, which is even greater than the one order magnitude that previous modeling results have suggested. Our analysis also demonstrates that the entrainment efficiency depends on the strength of the stratification of the EIL, but not on the TKE in the cloud top region. The relationships between entrainment efficiency and other STBL parameters serve as novel observational contraints for simulations of entrainment in such systems.
\end{abstract}

\section{Introduction}

Entrainment can be defined as "The process by which turbulent fluid... incorporates adjacent fluid that is nonturbulent, or much less turbulent; thus entrainment always proceeds toward the nonturbulent layer" (Glickman, 2000). Entrainment is an important process in the stratocumulus-topped boundary layer (STBL) because it causes the (more) turbulent layer, which is the cold and moist boundary layer, to incorporate air from the less turbulent free tropospheric air, which is warm and dry. The importance of entrainment is elegantly described by Lewellen and Lewellen (1998): "While cloud-top entrainment velocities are typically much smaller than their counterparts within the boundary layer $(\sim 1 \%)$, the temperature and humidity fluxes they give rise to are not. These entrainment fluxes can strongly affect the dynamics and cloud structures within the boundary layer; the resulting feedback can further increase these effects."

The presence and properties of the cloud layer therefore can depend on the rate of entrainment, as both warming and drying of the boundary layer tends to thin and potentially dissipate the cloud. The evaporation of cloud water caused by the warm, dry entrained air will change the microphysical properties of the cloud, most notably in the vicinity of cloud top, with potential impacts on the radiative and precipitation properties of the cloud layer.

One primary motivation for this work is that despite more than four decades of work since Lilly (1968), models, even high-resolution large eddy simulations (LES) with resolved scales of order $5 \mathrm{~m}$, do not accurately represent entrainment 
(Stevens et al., 2005). One factor is that the cloud top region often exhibits sharp gradients in thermodynamic properties such as potential temperature $\theta$ and total moisture $q_{\mathrm{t}}$, as well as dynamic properties such as turbulent kinetic energy (TKE). Another factor is the small scale and the correspondingly short duration of entrainment features, e.g. filaments of warm, dry air within the cloud layer. Accurately representing turbulence, and the associated entrainment, in such regions appears to be a great challenge for even our highestresolution models.

The entrainment interface layer (EIL) is a thin layer (typically a few tens of meters) that separates boundary layer and free tropospheric air and has properties that are intermediate between these two disparate air masses. It has been described from observations by a number of studies (e.g., Caughey et al., 1982; Wang and Albrecht, 1994; Nicholls and Turton, 1986; Lenschow et al., 2000; Gerber et al., 2005; Haman et al., 2007). One important role of the EIL is that it is likely to be the source of some (and possibly all) of the air that is entrained into the boundary layer (Haman et al., 2007). Thus, the thermodynamic and dynamic properties of the EIL are critical for understanding the role of entrainment in the evolution of the STBL. However, what governs the properties of the EIL remains poorly understood. Detrainment of boundary layer air into the free troposphere has been hypothesized as one mechanism for the formation of air with intermediate properties (Gerber et al., 2005; Deardorff et al., 1980), while other studies have found no evidence for detrainment (Faloona et al., 2005; Kurowski et al., 2009).

One way that observations can help our understanding of processes such as entrainment in stratocumulus is by providing constraints for models. Describing recent studies of stratocumulus, Stevens and Brenguier (2009) express this nicely: "...our ability to begin constraining the models with data... represents a significant step forward and provides an example of the increasingly critical interplay between models, theory, and data."

Our overarching interest in this study, therefore, is to both gain insight into the processes within the STBL, as well as generate novel constraints which can be used to test models and theory. Constraints derived from aircraft observations often come in the form of correlation, and lack clarity about the causation that leads to the observed relationships, which is often more easily explored through models. As a result, the synergy achieved by combining observations with models and theory is crucial for forwarding understanding of smallscale cloud processes.

Given the above, the two primary goals of this study are to (a) describe the observed vertical structure of the cloud top region, including the EIL and (b) identify and describe novel constraints on physical processes and parameters that are relevant to entrainment.

\subsection{Representation of entrainment}

The prediction of entrainment rate in the STBL has been the subject of many studies. The modern view of the STBL began more than forty years ago with Lilly (1968). The starting point for much of the theory of entrainment in stratocumulus is entrainment in cloud-free convective boundary layers, which are driven by surface heating and/or shear rather than cloud-top radiative cooling. The basic theoretical framework has been subsequently adapted for stratocumulus by incorporating new, relevant processes such as evaporation (e.g., Nicholls and Turton, 1986) (hereafter NT86) and buoyancy reversal (Deardorff, 1980; Randall, 1980). Typically, entrainment rate is represented by the entrainment velocity, $w_{\mathrm{e}}$, which is defined as the speed at which the boundary layer top incorporates fluid from the non-turbulent freetroposphere above it. In dry convective boundary layers, it has been proposed that $w_{\mathrm{e}}$ can be parameterized as (e.g., Wyngaard, 2010):

$\frac{w_{\mathrm{e}}}{U}=\frac{a}{R i_{U}}$

where $U$ is a scale velocity, $a$ is a constant determined by observation, and $R i_{U}$ is a Richardson number:

$R i_{U}=\frac{\frac{g}{\theta_{\mathrm{v}}} \Delta \theta_{\mathrm{v}} L}{U^{2}}$

where $L$ is a length scale, $\theta_{\mathrm{v}}$ is the virtual potential temperature and $\Delta \theta_{\mathrm{v}}$ is the change in $\theta_{\mathrm{v}}$ across the inversion. In boundary layer meteorology, $L$ is usually the boundary layer height $h$, and $U$ depends on the dominant process driving boundary layer turbulent mixing. For the STBL, the appropriate velocity scale is the convective velocity $w_{*}$, defined as (Stull, 1988):

$w_{*}=\left(2.5 \frac{g}{\overline{\theta_{\mathrm{v}}}} \int_{0}^{h} \overline{w^{\prime} \theta_{\mathrm{v}}^{\prime}} d z\right)^{1 / 3}$

The convective velocity describes the net production of turbulent kinetic energy through buoyancy effects within the boundary layer. This is generally viewed as the dominant term in the TKE equation because STBLs are maintained primarily through cloud-top longwave radiative cooling, which generates cold, dense, sinking air thereby producing mixing and turbulence in the boundary layer. There are, however, other processes that could contribute to TKE production, in particular wind shear.

NT86 evaluated a number of $w_{\mathrm{e}}$ parameterizations and they found that in general $w_{\mathrm{e}}$ tends to be underestimated relative to observed values, but a parameterization from Kraus and Schaller (1978) (hereafter KS78) generally did well (within $20 \%$ ) for four of the five observational cases. The KS78 parameterization relates $w_{\mathrm{e}}$ to a buoyancy flux ratio $\eta$, 
which we will term the entrainment efficiency:

$\eta=-\frac{\int_{0}^{h}\left(\overline{w^{\prime} \theta_{\mathrm{v}}^{\prime}}<0\right) d z}{\int_{0}^{h}\left(\overline{w^{\prime} \theta_{\mathrm{v}}^{\prime}}>0\right) d z}$

Physically, the numerator represents the total consumption of TKE in the vertical region within the boundary layer where there is net consumption of TKE. Near the top of the STBL, TKE is consumed when warm free tropospheric air pushes downwards into the cold boundary layer (i.e. entrainment) or when cold boundary layer air penetrates upwards into the free troposphere (i.e. detrainment). The denominator represents the total production of TKE (again, conditioned on that region where there is net production) due to the combination of sinking cold air parcels or rising warm air parcels (driven ultimately by cloud top longwave radiative cooling), which is assumed to be the source of the energy for entrainment. Thus, conceptually $\eta$ represents the fraction of the produced TKE (i.e. the denominator) that is consumed by entraining buoyant air (the numerator). The remainder of the TKE production $(1-\eta)$ is dissipated by other processes, such as driving boundary layer eddies.

The parameterization from KS78 assumes that other modes of TKE production such as shear are small relative to buoyancy production term. The KS78 parameterization assumes that $\eta=0.04$, i.e. can be represented as a constant, which was first proposed by Ball (1960) for dry convective boundary layers. Deardorff (1980) (hereafter Deardorff80) found from model simulations of the STBL that $\eta \sim 0.05$ but with strong variability (range of 0.01 to 0.09 ), i.e. $\eta$ varies by about a factor of 10. Analogously, experiments for dry convective layers have also found that in those situations, the so-called Ball ratio varies by about a factor of 5 (e.g., Betts and Ball, 1994). We also note that Lewellen and Lewellen (1998) propose a somewhat similar parameter but differs in that it emphasizes the large-scale eddy transport; evaluating their parameter from observations appears to be a significant challenge.

In this paper, we will explore entrainment using aircraft observations from the view point that buoyancy fluxes play a central role, in the spirit of KS78. Since Deardorff80 finds that $\eta$ ranges over about one order of magnitude, we seek to pursue more in-depth understanding of the parameters and processes that govern $\eta$ and are thus important for furthering our understanding of entrainment in STBLs. Understanding the relationship of $\eta$ with other physical variables is therefore one of the main goals of this study. On the other hand, while the results could have implications for the parameterization of entrainment, directly addressing this topic is not our main priority.

\subsection{Definitions of the boundary layer interface}

The definition of the EIL and hence its vertical extent have also been subjects of recent study. Analyzing results from a large-eddy simulation, Moeng et al. (2005) found that the cloud top altitude is lower than the altitude at which either liquid-water potential temperature $\left(\theta_{l}\right)$ or total water $\left(q_{\mathrm{t}}\right)$ gradients are maximum, which in turn is lower than the maximum altitude to which turbulent mixing is able to penetrate. The differences in these altitudes is a few tens of meters, but varies substantially. They suggest that the maximum turbulent-mixing altitude is most consistent with the traditional view of an entrainment interface because the definition of entrainment involves the interface of a turbulent flow with a non-turbulent one. Kurowski et al. (2009) reached the same conclusions regarding the vertical ordering of properties, also based on LES output. These studies lead to ambiguities in interpreting classic mixed-layer theory (e.g., Lilly, 1968), where it is generally assumed that all boundary layer properties abruptly change at the same altitude, typically just above cloud top. In this study, we address this same question using aircraft observations of the EIL region.

\section{Method}

Observations come from 16 flights of the Center for Interdisciplinary Remotely-Piloted Aircraft Studies (CIRPAS) Twin Otter during the Physics of Stratocumulus Top (POST) field campaign, which took place from mid-July to mid-August, 2008. The flights occurred in the NE Pacific approx. $100 \mathrm{~km}$ off the coast of Santa Cruz/Monterey, CA, typically bounded by $123^{\circ}$ to $124^{\circ} \mathrm{W}$ and $36^{\circ}$ to $37^{\circ} \mathrm{N}$. The flights were designed to study in detail the vertical structure of the stratocumulus top region. In order to achieve this, the bulk of each flight involved many sawtooth legs (Fig. 1) that spanned approx. $\pm 100 \mathrm{~m}$ of the visible cloud top. Note that cloud thickness was typically greater than $100 \mathrm{~m}$, so that the lowest altitude of the sawtooth legs was still within the cloud layer and thus the bottom-most portion of the stratocumulus deck was often not sampled. The ascent/descent rate during these legs was typically $1.5 \mathrm{~m} \mathrm{~s}^{-1}$, so that each sawtooth leg (either ascent or descent of $200 \mathrm{~m}$ altitude) required $2 \mathrm{~min}$ to complete. Approximately 60 sawtooth legs (either ascent or descent) are completed during a typical flight during a span of $\sim 2.5 \mathrm{~h}$. At the beginning and end of each flight, a slant profile of the atmosphere from the surface $(30 \mathrm{~m})$ to $1000 \mathrm{~m}$ was also conducted. Each flight also comprised a number of $10 \mathrm{~min}$ level legs at the surface and just below cloud base that are useful for estimating vertical fluxes near these boundaries.

This sampling strategy differs from that of many other aircraft studies of stratocumulus, during which level legs often comprise the bulk of the in-cloud sampling time. Level legs are useful because they permit estimation of large-scale averages across a horizontal distance of many boundary layer heights (a few tens or more), such as vertical turbulent fluxes of, for example, energy, moisture, buoyancy and momentum. Such a flight plan is also necessary in order to study the horizontal structure and variability within stratocumulus. 


\section{8}

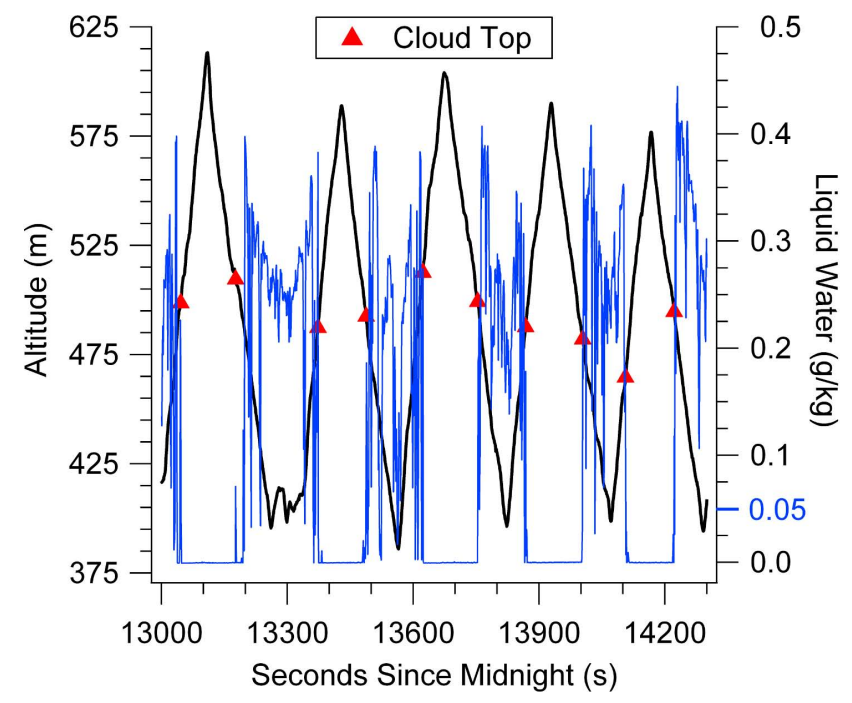

Fig. 1. Sample segment of a research flight during which the aircraft is performing sawtooth maneuvers across the stratocumulus cloud top. Black lines denote altitude and blue lines denote liquid water content. The red triangles mark the time and altitude of cloud top of $0.05 \mathrm{~g} \mathrm{~kg}^{-1}$ for each ascent or descent.

Without long level legs within the cloud, none of these objectives can be easily met.

The sawtooth flight pattern is conducive to obtaining detailed information about the vertical structure and variability of the STBL. In this case, the focus on the vertical profiles in the cloud top region, both in- and above-cloud, provides observations that would not be readily available from horizontal legs. Lenschow et al. (2000) previously utilized horizontal level legs and deduced small-scale vertical structure in the vicinity of cloud top by flying through the "corrugated" cloud top; their results span a region $\pm 12 \mathrm{~m}$ from cloud top, which is generally not enough to resolve the EIL with a vertical thickness of many tens of meters. The sawtooth flight strategy from POST complements past studies because of its focus on observing the vertical structure in detail, but over a large enough altitude range to capture important structures.

\subsection{Shifted altitude coordinate $z_{\mathrm{s}}$}

In order to synthesize the aircraft observations, we have binned the data by altitude using the cloud top as a reference. For each sawtooth leg (either ascent or descent), we find, using $1 \mathrm{~Hz}$ data (i.e. at $1.5 \mathrm{~m}$ vertical resolution), the uppermost altitude with a liquid water content of $0.05 \mathrm{~g} \mathrm{~m}^{-3}$, as illustrated in Fig. 1. This altitude defines the zero of our shifted altitude $\left(z_{\mathrm{s}}\right)$ coordinate for that sawtooth leg. Changing the threshold does not substantially alter the profiles. Altitudes above this cloud top are defined to be positive, while altitudes below (i.e. in-cloud) are negative. We then bin all the aircraft observations into $10 \mathrm{~m}$ bins, i.e. -100 to $-90 \mathrm{~m},-90$ to $-80 \mathrm{~m}, \ldots-10$ to $0 \mathrm{~m}, 0$ to $+10 \mathrm{~m}, \ldots 90$ to $100 \mathrm{~m}$. For a typ-

\section{J. K. Carman et al.: Observational constraints entrainment}

ical flight, this yields 300 to 400 observations at $1 \mathrm{~Hz}$ within each bin. We did some checks on whether decreasing the bin size from $10 \mathrm{~m}$ to $5 \mathrm{~m}$ would change the results, and do not see any evidence that the main results would be altered. This shifted altitude coordinate is useful because it yields a statistical view of the vertical structure of the cloud top region, while trying to account for variability in the altitude of cloud top over time (e.g. the STBL deepens over time if the entrainment rate exceeds the subsidence rate) or space (e.g. a east-west gradient in cloud top height due to the proximity of the continent along the eastern portion of the study area). For these reasons, referencing cloud top on a per-leg basis, rather than using a flight-averaged cloud top value, is preferable.

There are limitations of the cloud-top referenced altitude coordinate. Because the aircraft's ascent and descent occurs at a slow rate, the measured cloud-top altitude does not reflect the actual cloud top for the observations that came before or after crossing the cloud top boundary. During the $2 \mathrm{~min}$ it takes to complete one ascent or descent leg, the horizontal distance traveled is more than $6 \mathrm{~km}$. Thus, the shifted altitude coordinate does not properly take into account any variations in cloud top height that occur on scales smaller than this. As a result, the vertical profiles using this coordinate will experience some "smearing" of features; any sharp features (e.g. a jump in $\theta_{\mathrm{v}}$ ) that exist parallel to the cloud top may not be binned in such a way to exactly express the true sharpness of this feature. Despite this limitation, as we will show later, the altitude-shifted data do exhibit a number of sharp features, often within one or two 10-m altitude bins.

\subsection{Aircraft observations}

During POST, the CIRPAS Twin Otter flew a wide array of thermodynamic, dynamic and microphysical instrumentation. The standard CIRPAS facility instruments were used to measure winds, temperature, pressure, dew point temperature (from which water vapor mixing ratio $q_{\mathrm{v}}$ is derived) and cloud liquid water. Winds are measured using a 5-hole radome mounted on the nose of the aircraft; modifications were done to prevent cloud liquid water from clogging the pressure lines. Dew point temperature was measured using a chilled-mirror hygrometer, from which water vapor mixing ratio is derived. The response time of this hygrometer is quite slow, however $(\sim 2 \mathrm{~s})$ and so a LiCOR gas analyzer was also used to get water vapor with higher time resolution, but less absolute accuracy. Combining the chilled-mirror hygrometer, with its better accuracy, and the LiCOR instrument with faster response, yielded fast and accurate water vapor mixing ratio. For in-cloud $q_{\mathrm{v}}$, we do not utilize these measurements; instead we assume saturation at the measured temperature which removes any possible measurement difficulties due to the presence of liquid water. Cloud liquid water was measured using the facility standard Gerber PVM-100A (Gerber et al., 1994). Most of the above observations are 


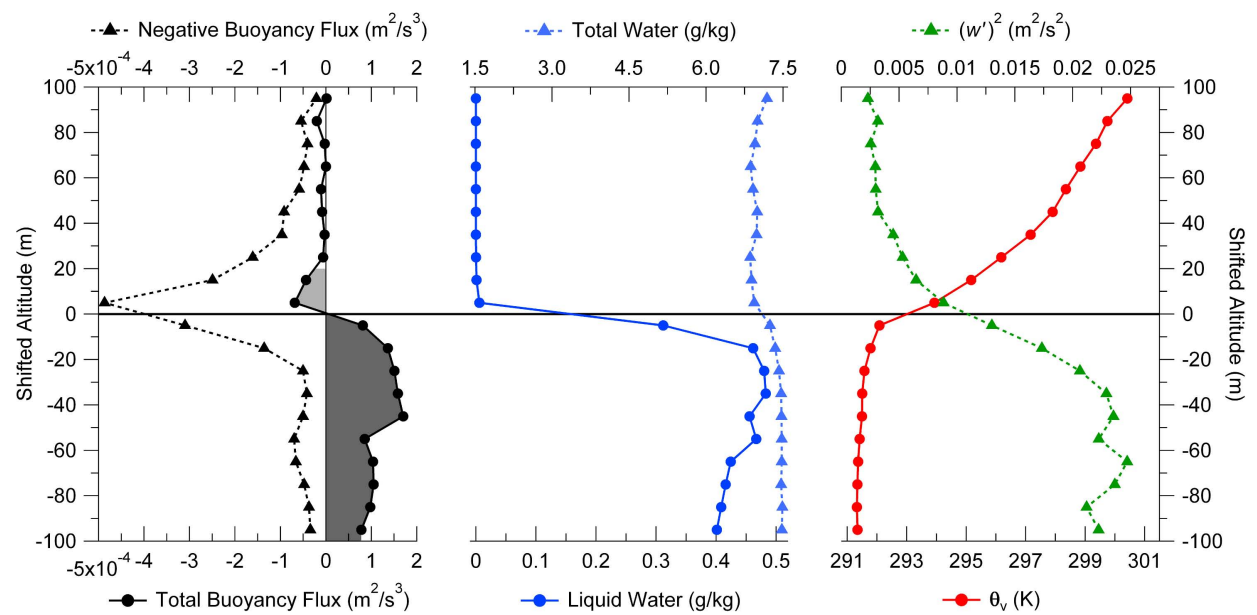

Fig. 2. Whole-flight averaged vertical profiles for 21 July 2008 of (left to right): the sum of only negative buoyancy fluxes; the net buoyancy flux (with altitudes of net negative and positive buoyancy fluxes shaded); total water; liquid water; $\overline{\left(w^{\prime}\right)^{2}}$; and virtual potential temperature. The vertical coordinate is the shifted altitude $z_{\mathrm{s}}$ where the liquid water cloud top is defined as $0 \mathrm{~m}$.

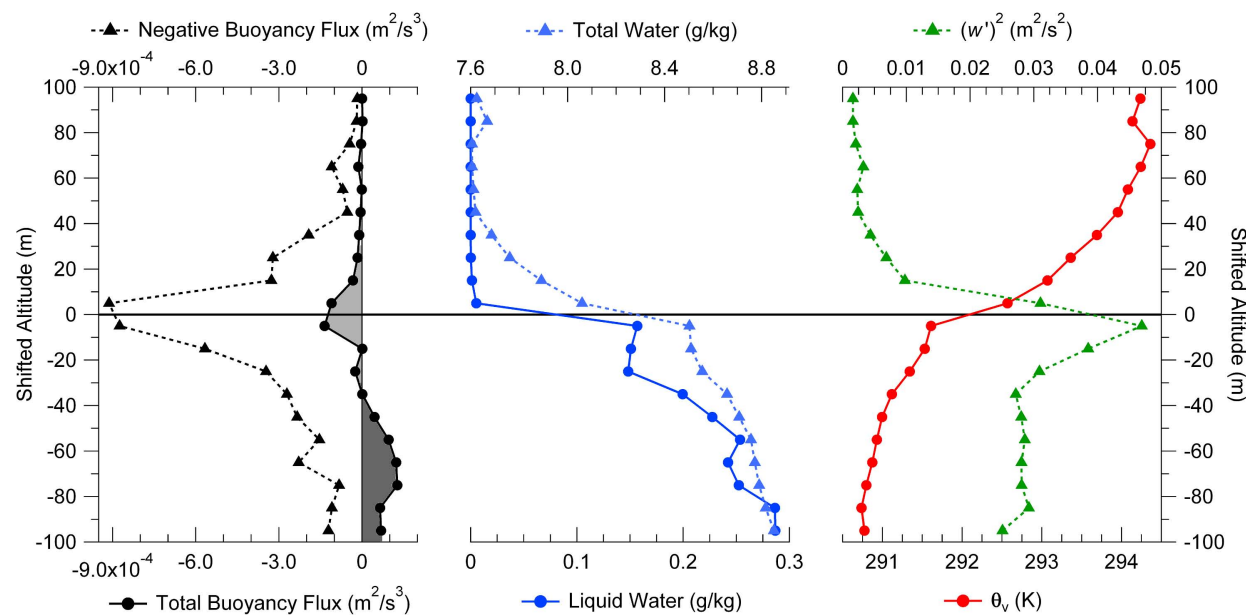

Fig. 3. Whole-flight averaged vertical profiles for 27 July 2008 of (left to right): the sum of only negative buoyancy fluxes; the net buoyancy flux (with altitudes of net negative and positive buoyancy fluxes shaded); total water; liquid water; $\overline{\left(w^{\prime}\right)^{2}}$; and virtual potential temperature. The vertical coordinate is the shifted altitude $z_{\mathrm{s}}$ where the liquid water cloud top is defined as $0 \mathrm{~m}$.

acquired at $40 \mathrm{~Hz}$; this can then be used as-is, or averaged to $10 \mathrm{~Hz}$ or $1 \mathrm{~Hz}$ for convenience. Cloud drop size distributions are inferred from observations utilizing the Artium Flight Phase-Doppler-Interferometer (F/PDI) (Chuang et al., 2008), which measures the size of individual drops using the phaseDoppler interferometry technique (Bachalo, 1980; Bachalo et al., 1984; Sankar et al., 1991). The F/PDI and PVM-100A measurements can be used to check each other; we find during POST that the two instruments generally agree well once the difference in measured drop size range is accounted for, increasing our confidence in both data sets.

For four example days (Figs. 2 to 5), observations of the vertical structure of total water mixing ratio $q_{\mathrm{t}}$, liquid water mixing ratio $q_{1}$, virtual potential temperature $\theta_{\mathrm{v}}$ and the vertical component of TKE $\overline{\left(w^{\prime}\right)^{2}}$ are plotted as a function of shifted altitude. All profiles are averaged over the entire flight. The four days are selected in order to represent a range of qualitative behavior. In general, about 300 to $400 \mathrm{~s}$ of data goes into each $10 \mathrm{~m}$ altitude bin, and data are all collected within a 2.7 to $3.5 \mathrm{~h}$ period. Table 1 describes basic details for all flights.

For this study, the liquid water is derived from integrating the PDI size distributions because it includes drops up to $\sim 100 \mu \mathrm{m}$ diameter, much larger than the cutoff for the PVM-100A of 30 to $40 \mu \mathrm{m}$ (Wendisch et al., 2002). Liquid water from drops larger than $100 \mu \mathrm{m}$ are not included; under the range of drizzle rates observed $\left(10^{-3}\right.$ to $1 \mathrm{~mm}$ day $\left.^{-1}\right)$, 


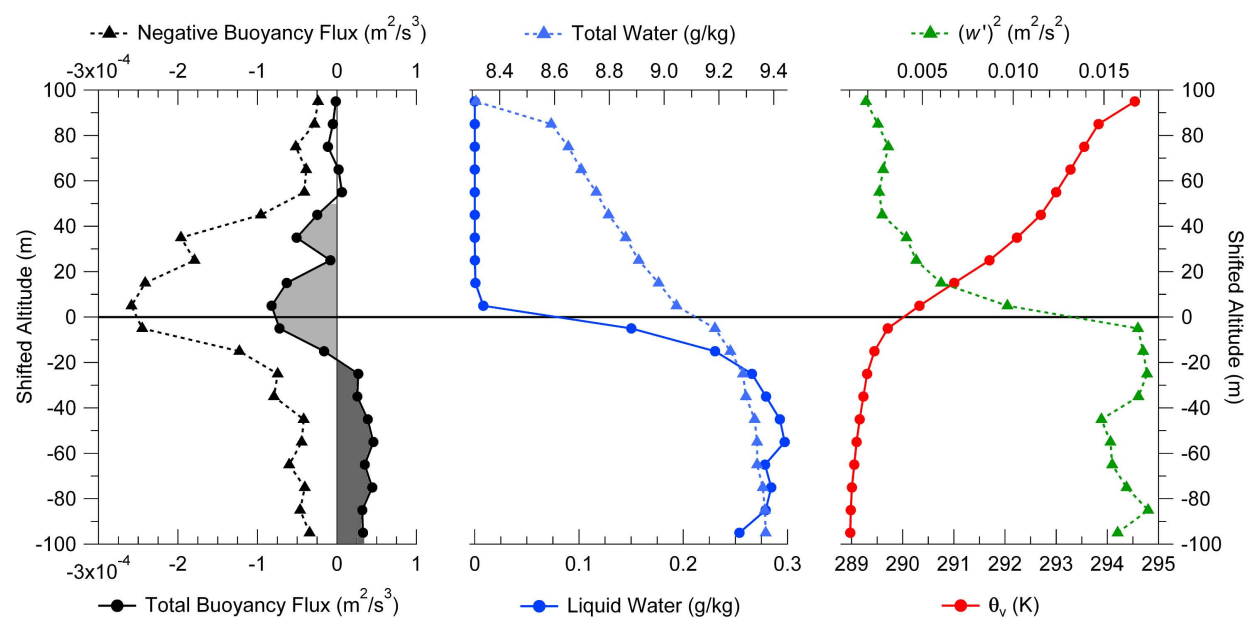

Fig. 4. Whole-flight averaged vertical profiles for 30 July 2008 of (left to right): the sum of only negative buoyancy fluxes; the net buoyancy flux (with altitudes of net negative and positive buoyancy fluxes shaded); total water; liquid water; $\overline{\left(w^{\prime}\right)^{2}}$; and virtual potential temperature. The vertical coordinate is the shifted altitude $z_{\mathrm{s}}$ where the liquid water cloud top is defined as $0 \mathrm{~m}$.

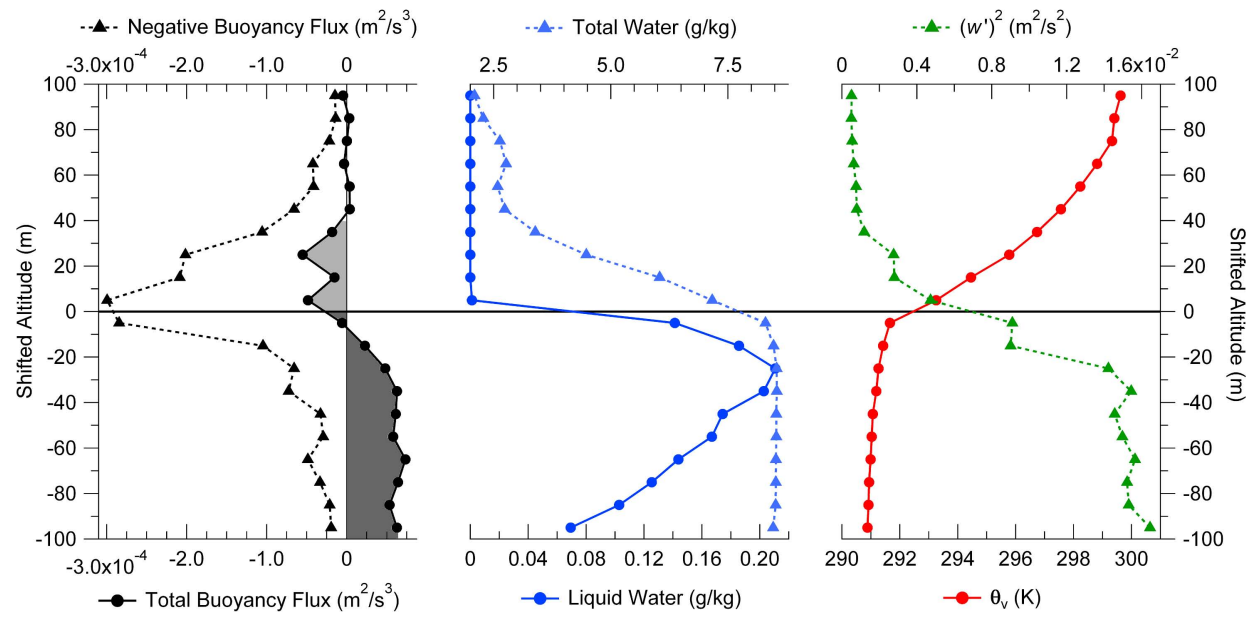

Fig. 5. Whole-flight averaged vertical profiles for August 6, 2008 of (left to right): the sum of only negative buoyancy fluxes; the net buoyancy flux (with altitudes of net negative and positive buoyancy fluxes shaded); total water; liquid water; $\overline{\left(w^{\prime}\right)^{2}}$; and virtual potential temperature. The vertical coordinate is the shifted altitude $z_{\mathrm{s}}$ where the liquid water cloud top is defined as $0 \mathrm{~m}$.

the contribution from these sizes is unlikely to be significant. Total water is computed as $q_{\mathrm{t}}=q_{\mathrm{v}}+q_{1}$.

For all flights, the profile of $\theta_{\mathrm{v}}$ typically increases slowly with altitude in the mixed layer, then sharply increases near cloud top, then transitions to a less sharp, but still increasing, slope far above cloud top. A substantial increase in $\theta_{\mathrm{v}}$ in the few tens of meters above cloud top occurs (e.g. Figs. 2 to 5), with a range of approximately 3 to $10 \mathrm{~K}$. The The values for $\overline{\left(w^{\prime}\right)^{2}}$ jump from higher boundary layer values $(\sim 1$ to $4 \times 10^{-2} \mathrm{~m}^{-2} \mathrm{~s}^{-2}$ ) to much lower values (by a factor of $\sim 5$ to 10 , usually closer to 10 ) in the free troposphere. Roughly constant values with height are found in the regions wellbelow and -above the transition. Maximum cloud top liquid water ranges from 0.2 to $0.5 \mathrm{~g} \mathrm{~kg}^{-1}$, with typical values be- tween 0.3 and $0.4 \mathrm{~g} \mathrm{~kg}^{-1}$. Jumps in total water are much less predictable than those for $\theta_{\mathrm{v}}$ or $\overline{\left(w^{\prime}\right)^{2}}$. There are five flights (out of sixteen total) during which the free tropospheric air has on average very nearly the same $q_{\mathrm{t}}$ (within $1 \mathrm{~g} \mathrm{~kg}^{-1}$ ) as the boundary layer, and another two where the moisture inversion is less than $2 \mathrm{~g} \mathrm{~kg}^{-1}$, at least within the $\sim 100 \mathrm{~m}$ above cloud top that the sawtooth flight pattern covered. During the other nine flights, the free tropospere is substantially drier than the boundary layer, with $\Delta q_{\mathrm{t}}$ ranging from 3 to $6 \mathrm{~g} \mathrm{~kg}^{-1}$, with typical values of 4 to $5 \mathrm{~g} \mathrm{~kg}^{-1}$. 
Table 1. Information for each flight. Cloud top denotes mean and standard deviation of cloud top used for the altitude shifting the sawtooth data. The start and end times identify the beginning and end of the sawtooth legs, not the takeoff and landing times. These times are all listed as local time (Pacific Daylight Time). UTC $=$ PDT $+7 \mathrm{~h}$. The day flights typically are on station in the vicinity of mid-day, while the night flights are on station from before sundown to mid-evening. Sunset ranges from 20:30 PDT in mid-July to 20:00 PDT in mid-August. The * denotes flights presented in Figs. 2 to 5.

\begin{tabular}{cccccccc}
\hline Date & Cld Base, $\mathrm{m}$ & Cld Top, $\mathrm{m}$ & $\mathrm{H}, \mathrm{m}$ & ${\text { LWP, } \mathrm{g} \mathrm{m}^{-2}}$ & Start time & End time & Duration \\
\hline $16 / 07 / 2008$ & 180 & $470 \pm 19$ & 290 & 98 & $11: 16$ & $14: 22$ & $03: 06$ \\
$17 / 07 / 2008$ & 280 & $444 \pm 30$ & 160 & 41 & $11: 43$ & $14: 48$ & $03: 05$ \\
$18 / 07 / 2008$ & 240 & $479 \pm 17$ & 240 & 69 & $19: 02$ & $21: 42$ & $02: 40$ \\
$21 / 07 / 2008^{*}$ & 340 & $937 \pm 33$ & 600 & 96 & $11: 32$ & $13: 44$ & $02: 12$ \\
$27 / 07 / 2008^{*}$ & 180 & $432 \pm 53$ & 250 & 55 & $19: 07$ & $22: 03$ & $02: 56$ \\
$28 / 07 / 2008$ & 300 & $570 \pm 55$ & 270 & 92 & $18: 56$ & $22: 26$ & $03: 30$ \\
$30 / 07 / 2008^{*}$ & 130 & $322 \pm 32$ & 190 & 59 & $11: 22$ & $15: 04$ & $03: 42$ \\
$01 / 08 / 2008$ & 90 & $369 \pm 54$ & 280 & 51 & $11: 08$ & $14: 46$ & $03: 38$ \\
$04 / 08 / 2008$ & 370 & $614 \pm 40$ & 240 & 66 & $11: 23$ & $14: 14$ & $02: 51$ \\
$06 / 08 / 2008 *$ & 380 & $532 \pm 39$ & 150 & 17 & $18: 49$ & $21: 50$ & $03: 01$ \\
$07 / 08 / 2008$ & 460 & $713 \pm 55$ & 250 & 63 & $19: 14$ & $22: 23$ & $03: 09$ \\
$08 / 08 / 2008$ & 250 & $599 \pm 42$ & 350 & 135 & $19: 28$ & $22: 19$ & $02: 51$ \\
$11 / 08 / 2008$ & 130 & $510 \pm 28$ & 380 & 160 & $19: 15$ & $22: 23$ & $03: 08$ \\
$12 / 08 / 2008$ & 150 & $473 \pm 35$ & 320 & 53 & $19: 17$ & $22: 04$ & $02: 47$ \\
$14 / 08 / 2008$ & 140 & $426 \pm 27$ & 290 & 84 & $11: 28$ & $14: 20$ & $02: 52$ \\
$15 / 08 / 2008$ & 140 & $421 \pm 24$ & 280 & 77 & $10: 30$ & $13: 14$ & $02: 44$ \\
\hline
\end{tabular}

Table 2. Summary of correlations among parameters that relate to cloud top entrainment. All values are of the correlation coefficient $R^{2}$ and the sign (+ or -) after the value denotes whether the correlations are positive or negative. Values in boldface highlight the strongest correlations. The value denoted by ${ }^{*}$ is obtained by throwing out one outlier (see text for details); $R^{2}=0.2$ if the outlier is included.

\begin{tabular}{cccccc}
\hline & $\eta$ & $\int-F_{\mathrm{b}}$ & $\int+F_{\mathrm{b}}$ & $d \theta_{\mathrm{v}} /\left.d z\right|_{\max }$ & $\overline{\left(w^{\prime}\right)_{\mathrm{CT}}^{2}}$ \\
\hline $\int-F_{\mathrm{b}}$ & $\mathbf{0 . 8 +}$ & - & - & - & - \\
$\int+F_{\mathrm{b}}$ & $\mathbf{0 . 5}-$ & none & - & - & - \\
$d \theta_{\mathrm{v}} /\left.d z\right|_{\max }$ & $\mathbf{0 . 5}-$ & $\mathbf{0 . 5}-^{*}$ & $\mathbf{0 . 6 +}$ & - & - \\
$\frac{\left(w^{\prime}\right)_{\mathrm{CT}}^{2}}{\frac{\left(w^{\prime}\right)_{\mathrm{BL}}^{2}}{n}}$ & $0.2+$ & $\mathbf{0 . 5 +}$ & none & none & - \\
\hline
\end{tabular}

\subsubsection{Computation of (filtered) vertical fluxes}

Proper computation of vertical fluxes generally requires long horizontal legs ( $\sim 10 \mathrm{~min}$, equivalent to $30 \mathrm{~km}$ on the Twin Otter) such that appropriate statistics can be constructed. The disadvantage is that the vertical structure of these fluxes can not be resolved in much detail. Due to the sawtooth flight pattern during POST, such long level legs were not performed, and thus any fluxes we compute will be spatially filtered, i.e. represent vertical turbulent fluxes at spatial scales smaller than some characteristic length scale. We use the following method $^{1}$ to compute these filtered buoyancy fluxes:

\footnotetext{
${ }^{1}$ We considered using an alternate method for computing fluxes, whereby we accumulate $w$ and $\theta_{\mathrm{V}}$ values in each altitude-shifted $10 \mathrm{~m}$ vertical bin. If we then made the assumption that the cloud layer was at steady state and had no horizontal gradients, we could compute $\bar{w}, w^{\prime}, \overline{\theta_{\mathrm{v}}}$, and $\theta_{\mathrm{v}}^{\prime}$ and thus estimate $\overline{w^{\prime} \theta_{\mathrm{v}}^{\prime}}$. However, it was
}

1. Compute $\bar{w}$ and $\overline{\theta_{\mathrm{v}}}$ for each 2 -s interval using the $40 \mathrm{~Hz}$ data set, which corresponds to a period where the altitude change is $\sim 3 \mathrm{~m}$, while the horizontal distance travelled is $110 \mathrm{~m}$. The latter value sets the characteristic length scale for the filtered fluxes.

2. Compute $w^{\prime}$ and $\theta_{\mathrm{v}}^{\prime}$ as usual from $40 \mathrm{~Hz}$ data, e.g. $w^{\prime}=w-\bar{w}$.

3. Compute $\overline{w^{\prime} \theta_{\mathrm{v}}^{\prime}}$.

4. We now treat each 2-s value as a single average value, which we then bin into shifted altitude bins as described above.

It is important to note that in step \#1, we compute the mean values using a very short interval in time $(2 \mathrm{~s})$ rather than felt that neither of these assumptions could be readily defended and thus this method was ultimately not used. 
an interval of $10 \mathrm{~min}$ that is required for estimation of a true large-scale average. As a result, our turbulent fluxes only represent small-scale turbulent fluxes, i.e. turbulent fluxes that are filtered for length scales smaller than $100 \mathrm{~m}$. Since the boundary layer height during POST averaged $\sim 500 \mathrm{~m}$, turbulent eddies much greater than our filtered length scale of $100 \mathrm{~m}$ will contribute, and most likely dominate, the true turbulent fluxes within the boundary layer. As a result, our computed fluxes only represent a subset of the true turbulent flux. All references to measured turbulent fluxes below are implicitly filtered fluxes unless specifically noted. We will evaluate whether these fluxes, despite their limitations, are useful and meaningful below.

Because the aircraft is always ascending or descending, and because some of the scalars are not constant with height, especially in the vicinity of cloud top, choosing a longer time interval to compute $\bar{w}$ or $\overline{\theta_{\mathrm{v}}}$ has the potential to cause the computed turbulent fluxes to increase simply because of the vertical gradient in $\bar{w}$ and $\overline{\theta_{\mathrm{v}}}$, leading to artificially large values of $w^{\prime}$ or $\theta_{\mathrm{v}}^{\prime}$. We chose an averaging time of 2-s (corresponding to $\sim 3 \mathrm{~m}$ vertical change in the aircraft) because this is the largest value we were comfortable using (and thus maximizing the filtering length scale) without introducing biases in the flux calculations due to mean vertical gradients. In the STBL, $d \bar{w} / d z$ is generally very small since the large-scale divergence is small and thus vertical gradients of $\bar{w}$ will not artificially inflate the computed fluxes. In contrast, vertical gradients in $\theta_{\mathrm{v}}$ can be substantial, particularly within the EIL. With our 2-s averaging time, we find that the mean magnitude of $\theta_{\mathrm{v}}^{\prime}$ is $0.05 \mathrm{~K}$, which appears in line with typically-observed values (e.g. Fig. 1 in NT86). Thus we conclude that the observations do not show a substantial bias at the 2-s averaging period in our buoyancy flux calculation method.

Figures 2 to 5 show example profiles of filtered vertical turbulent buoyancy flux $F_{\mathrm{b}}=\left(g / \theta_{\mathrm{v}}\right) \overline{w^{\prime} \theta_{\mathrm{v}}^{\prime}}$. For each altitude bin, all flux values are averaged over the entire flight. Also plotted is the mean negative buoyancy flux, which averages only those 2-s values of buoyancy flux in each altitude bin which are negative. The negative buoyancy flux profiles illustrated in these figures are consistent with theory. The values peak very near to cloud top and decrease to much smaller values within a few tens of meters on either side. The qualitative agreement with theory increases our confidence that these filtered fluxes are meaningful.

In general, the total buoyancy flux is positive at lower altitudes within the cloud (i.e. potential energy is released), and then becomes negative (i.e. TKE is doing work against stably stratified air) somewhere around cloud top (as illustrated in Figs. 2 to 5) . Above $z_{\mathrm{s}} \sim 20$ to $40 \mathrm{~m}$, the total buoyancy flux becomes very close to zero, reflecting the very low turbulence in this region. This behavior is consistent with theoretical predictions for the STBL (e.g. Deardorff80). The magnitude of the total buoyancy flux in the vicinity of cloud top (i.e. where net buoyancy flux is negative) shows values that are in the range of $-10^{-4} \mathrm{~m}^{2} \mathrm{~s}^{-3}$, which is between a similar order- of-magnitude to a factor of 3 less than predicted by LES (e.g. Deardorff80, Bretherton et al., 2007), though it is also known that LES generally over-predicts entrainment (Stevens et al., 2005). The filtered net negative buoyancy flux more closely matches model predictions, which is consistent with the notion that entrainment tends to be a small-scale event, with typical length scales on the order of $\sim 10$ to $30 \mathrm{~m}$ based on high resolution observations of liquid water and temperature near the tops of stratocumulus (Gerber et al., 2005; Haman et al., 2007). Thus, the filtering will have less of an impact on the computed flux and thereby better match model predictions. Within the boundary layer, where the total buoyancy flux is generally positive, it is expected that eddies comparable to or larger than the boundary layer height, $\sim 500 \mathrm{~m}$, and much larger than the $100 \mathrm{~m}$ length scale, will contribute most of the flux. Thus the filtered fluxes in this region are likely to underestimate the true fluxes by a larger fraction than in the entrainment region, where smaller scales dominate. The computed positive values of the total buoyancy flux in Figs. 2 to 5 are in the range of $10^{-4} \mathrm{~m}^{2} \mathrm{~s}-3$ (i.e. very similar to the negative net buoyancy fluxes), which is approximately a factor of 10 to 20 lower than predicted by LES (e.g. Deardorff80, Bretherton et al., 2007). Spatially filtering the fluxes, therefore, overestimates the entrainment efficiency since the denominator in Eq. (4) will be more greatly underestimated than the numerator, by a factor of roughly one order of magnitude.

The KS78 framework assumes that buoyancy production dominates the TKE budget. During POST, boundary layer values of $d \bar{U} / d z$ range from 2 to $7 \times 10^{-3} \mathrm{~s}^{-1}$, from which we estimate that shear production of TKE is approximately one order of magnitude less than buoyancy production, which satisfies the KS78 assumption.

Other studies have also used the equivalent to filtered fluxes. For example, Kurowski et al. (2009) analyzed LES model output by looking at fields of the flow enstrophy, which focuses on small-scale turbulent motions. They find that enstrophy is useful for identifying the turbulent part of the EIL. We also note that studies utilizing LES compute fluxes by combining two different calculations: the first is the flux from the resolved scales, which incorporates length scales larger than the grid spacing; the second are the subgrid scale fluxes, which are parameterized rather than explicitly calculated from basic equations because they occur on length scales smaller than the grid spacing. In this way, the filtered fluxes contained in this study may be helpful to understanding or constraining the sub-grid scale fluxes, especially because these parameterized fluxes appear to have difficulty near sharp gradients, such as in the vicinity of cloud top. 


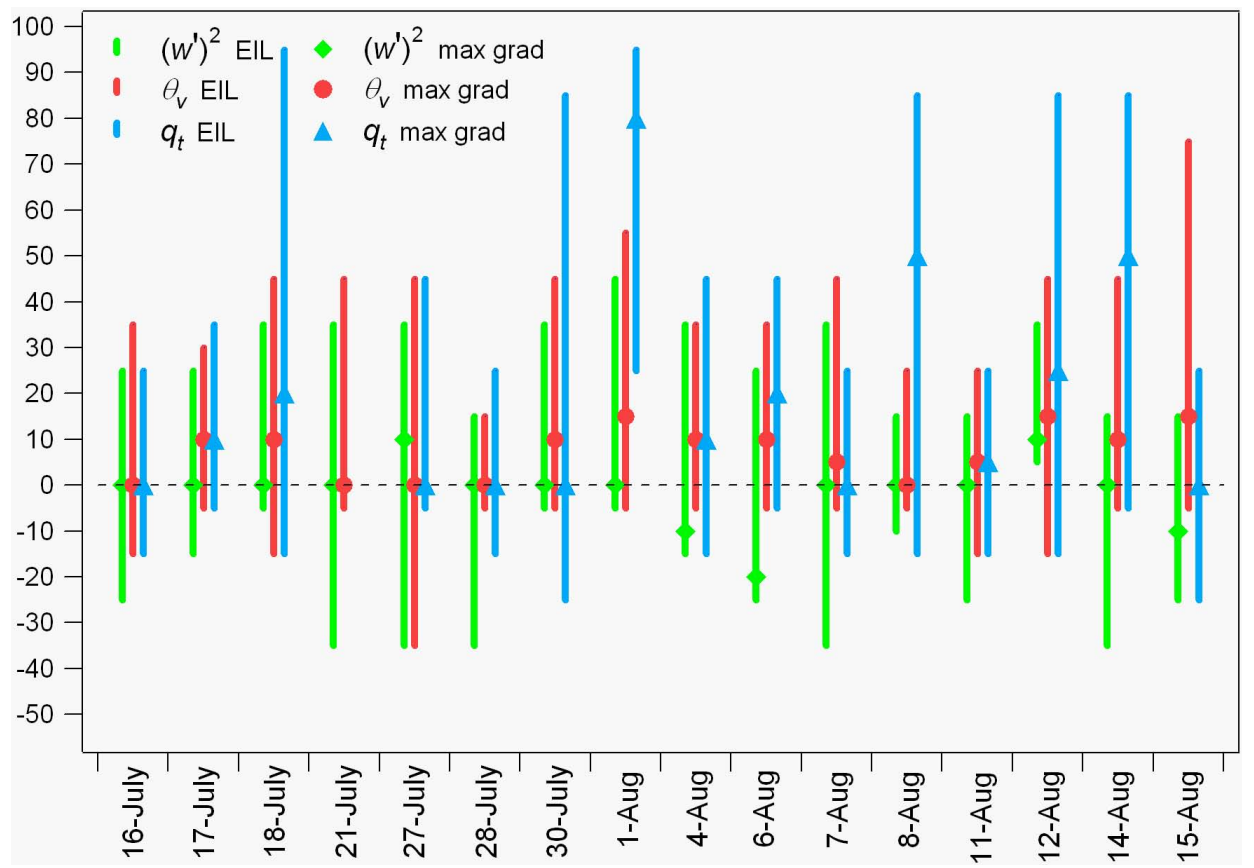

Fig. 6. EIL as defined by three different variables as a function of shifted altitude. The symbol shows the altitude of the maximum gradient in that quantity, and the bars represent the extent of the EIL estimated using the three different variables. All data is averaged over the entire day. For 21 July, no $q_{\mathrm{t}}$ EIL could be identified because $q_{\mathrm{t}}$ was constant throughout the entire vertical profile $( \pm 100 \mathrm{~m})$ of the cloud top region.

\section{Results}

\subsection{EIL properties}

We first use the aircraft observations to examine the vertical structure of the EIL. We will test the results of Moeng et al. (2005) and Kurowski et al. (2009) regarding the different definitions of the boundary layer top, which we equate to the EIL top. We define the EIL as the thin region between the boundary layer and the free troposphere where strong gradients in properties such as $\theta_{\mathrm{v}}, q_{\mathrm{t}}$ and $\overline{\left(w^{\prime}\right)^{2}}$ are located. Note that this location may not be the same for $q_{\mathrm{t}}$ and $\overline{\left(w^{\prime}\right)^{2}}$, for example. Identifying the altitude where, say, $q_{\mathrm{t}}$ starts to decrease from a value representative of the boundary layer does involve some subjective decisions; we tried to minimize the subjectivity by having the two primary authors involved separately pick out these values and any discrepancies are dealt with by discussion. We estimate the uncertainty typically to be between 10 and $20 \mathrm{~m}$ based on examination of the vertical profiles, although in some cases the altitude where the transition occurs is very clear (e.g. the bottom of the EIL appears well-defined for $\overline{\left(w^{\prime}\right)^{2}}$ in Fig. 4), and there exist other cases where the boundary is highly ambiguous (e.g. both the bottom and top of the EIL based on $q_{\mathrm{t}}$ in the same figure). Locating the altitude of the maximum vertical gradient in any of these quantities is in almost all cases substantially easier and the uncertainty should typically be about the resolution of the binned data, $10 \mathrm{~m}$.
Data averaged over entire flights are used in this analysis. If we break each flight by time into three segments, the exact values can differ, but the overall conclusions are the same.

\subsubsection{Turbulence EIL}

Figure 6 shows the results comparing the EIL region altitudes versus shifted altitude for each of the three quantities used to identify the EIL: $\theta_{\mathrm{v}}, q_{\mathrm{t}}$ and $\overline{\left(w^{\prime}\right)^{2}}$. For each quantity, we identify the bottom and top of the EIL, as well as the altitude at which the maximum gradient is found. For the $\overline{\left(w^{\prime}\right)^{2}}$ (or turbulence) EIL, we find that the transition from high boundary layer TKE to lower free troposphere TKE almost always begins below cloud top, at $z_{\mathrm{s}}$ between -5 and $-35 \mathrm{~m}$ (average of $-20 \mathrm{~m}$ ). The top of the turbulence EIL typically spans from 15 to $35 \mathrm{~m}$ (average of $30 \mathrm{~m}$ ). Thus, the EIL as defined by turbulence is typically $\sim 50 \mathrm{~m}$ in thickness, and straddles the liquid water interface. In 11 of 16 cases, the maximum gradient in $\overline{\left(w^{\prime}\right)^{2}}$ occurs exactly at the estimated cloud top $\left(z_{\mathrm{s}}=0\right)$, while all but one of the remaining cases show this gradient to be within $10 \mathrm{~m}$ of cloud top. Because cloud-top radiative cooling is the primary mechanism for TKE generation in the STBL and is concentrated in the top few tens of meters of the cloud, it makes sense that turbulence only begins to drop right near cloud top, and then steeply decreases once the liquid water interface is reached. 


\subsubsection{Buoyancy EIL}

The $\theta_{\mathrm{v}}$ EIL appears to correlate well with the turbulence EIL. For all days, the $\theta_{\mathrm{v}}$ EIL starts below cloud top at $z_{\mathrm{s}}$ between -5 and $-15 \mathrm{~m}$ in most cases, with an average of $-10 \mathrm{~m}$. This is $10 \mathrm{~m}$ higher than the bottom of the turbulence EIL. The top of the $\theta_{\mathrm{v}}$ EIL typically sits between $z_{\mathrm{s}}$ of 25 and $45 \mathrm{~m}$ (average of $40 \mathrm{~m}$ ), which is also higher than the turbulence EIL by about $10 \mathrm{~m}$, and thus the mean thickness is approximately the same, $\sim 50 \mathrm{~m}$. Looking at the individual days, on 9 out of 16 flights, the lower boundary of the w' and $\theta_{\mathrm{v}}$ EILs are within $10 \mathrm{~m}$ of each other. For 6 of the 7 remaining cases, the bottom of the $\theta_{\mathrm{v}}$ EIL is either 20 or $30 \mathrm{~m}$ above that of the turbulence EIL. One interpretation of this result is that entrainment, which draws high $\theta_{\mathrm{v}}$ air into the boundary layer, is slow enough that its effects are only seen in the top $10 \mathrm{~m}$ of the cloud layer. Below this altitude, mixing is faster and thus causes the original entrained air to be spread throughout the remainder of the mixed layer and thus no strong gradient in $\theta_{\mathrm{v}}$ remains. The altitude of the maximum gradient in $\theta_{\mathrm{v}}$ is, similarly, slightly higher than that for turbulence. While in six of 16 cases the $\theta_{\mathrm{v}}$ maximum gradient is at $z_{\mathrm{s}}=0 \mathrm{~m}$, for the remaining cases it is between 5 and $15 \mathrm{~m}$, with an overall average of $7 \mathrm{~m}$.

\subsubsection{Moisture EIL}

Defining the EIL boundaries based on total water $q_{\mathrm{t}}$ appears to be much less reliable than $\theta_{\mathrm{v}}$ or turbulence. One common example is shown in Fig. 4. Here, water vapor begins to decrease in the vicinity of cloud top, but the slope is very shallow, exhibiting a decrease in $q_{\mathrm{t}}$ of only $0.6 \mathrm{~g} \mathrm{~kg}^{-1}$ in the $90 \mathrm{~m}$ above cloud top, with no obvious jump. By any other measure during that flight, the EIL appears to be substantially shallower. Figure 2 shows an extreme example, where there is almost no change in $q_{\mathrm{t}}$ across cloud top even though there are reasonably sharp changes in the other quantities. For those six days for which the top boundary of the $q_{\mathrm{t}}$ EIL is far above cloud top $\left(z_{\mathrm{s}}>80 \mathrm{~m}\right)$ in Fig. 6 this indicates a $q_{\mathrm{t}}$ profile similar to 30 July whereby the top of the EIL was difficult to establish. In all of these six cases, a clear value for the EIL top was difficult to choose and thus should be viewed as highly uncertain. With 21 July not providing any way to estimate the EIL top, the nine remaining cases do show reasonably good agreement with the $\theta_{\mathrm{v}}$-defined EIL. For example, on average the bottom boundary of the $q_{\mathrm{t}}$-defined EIL is also about $10 \mathrm{~m}$ above that defined by turbulence and similar to that defined by $\theta_{\mathrm{v}}$ for these nine cases. The maximum gradient in $q_{\mathrm{t}}$ does have a tendency to be further above cloud top than that for either $\theta_{\mathrm{v}}$ or turbulence, although the most common altitude for the $q_{\mathrm{t}}$ maximum gradient is $z_{\mathrm{s}}=0$, just as for the other quantities.

In general, it was surprising how often the free tropospheric air exhibited high humidities. As described above, many of the jumps in $q_{\mathrm{t}}$ were surprisingly small, with five flights showing jumps less than $1 \mathrm{~g} \mathrm{~kg}^{-1}$, and two more exhibiting jumps less than $2 \mathrm{~g} \mathrm{~kg}^{-1}$. Even more surprising was the one day (16 July) where the free tropospheric air was moister than in the boundary layer by around $1 \mathrm{~g} \mathrm{~kg}^{-1}$. This leaves only half of the flights with a more canonical 2 to $6 \mathrm{~g} \mathrm{~kg}^{-1}$ decrease in $q_{\mathrm{t}}$ across the EIL. It is important to realize that the POST flights are not an unbiased sampling of the atmosphere, but biased to the presence of stratocumulus. Therefore, it is not surprising that $\theta_{\mathrm{v}}$ always exhibits a reasonably strong jump or gradient at cloud top; if this didn't exist, then the boundary layer would most likely grow quickly by entrainment, leading to drying and eventually dissipation of the cloud layer. However, a strong decrease in $q_{\mathrm{t}}$ is not a necessary condition for stratocumulus, and thus a wider range of behavior is possible.

\subsubsection{Comparison of EIL tops}

We next compare our observations of the EIL top with results derived from LES. We define the altitude of the EIL top as $z_{\theta v}, z_{\mathrm{q}}$ and $z_{\text {turb }}$, for the three different variables found in Fig. 6. Besides cloud top $z_{1 w c}$ (which is defined here as shifted altitude $z_{\mathrm{s}}=0$ ), Moeng et al. (2005) define two other measures of the top of the boundary layer: $z_{\text {mix }}$, which is the maximum height to which turbulent eddies penetrate; and $z_{\mathrm{mgd}}$ which is the altitude at which some tracer shows the maximum gradient. Their simulations predict that $z_{\text {mix }}>z_{\text {mgd }}>z_{\text {lwc }}$ Observations are not able to identify $z_{\text {mix }}$ because this is achieved in the simulations by the release of idealized tracers. Instead, we utilize more observationallyoriented definition of the EIL top described above and as shown in Fig. 6. We assume $z_{\mathrm{q}}$ is equivalent to $z_{\text {mix }}$ since moisture is one way to track boundary layer air (but likely not as reliable as dimethylsulfide, for example (Faloona et al., 2005), and that $z_{\text {turb }}$ is analogous to $z_{\mathrm{mgd}}$, albeit shifted slightly upwards as it represents the EIL top rather than maximum gradient.

We find that cloud top $z_{1 \mathrm{wc}}$ is, on average, below both $z_{\mathrm{q}}$ and $z_{\text {turb }}$ for all cases, in agreement with Moeng et al. (2005). For a majority of cases, $z_{\mathrm{q}}$ and $z_{\text {turb }}$ are within $10 \mathrm{~m}$ of each other, which given that this is our vertical bin resolution, is indicative that they are approximately the same altitude. There is no clear preference for $z_{\mathrm{q}}$ to be larger than $z_{\text {turb }}$ when the two values are close, which is a slightly different result from Moeng et al. (2005). However, for those six cases where $z_{\mathrm{q}}$ and $z_{\text {turb }}$ differ by more than $10 \mathrm{~m}$, in every single case $z_{\mathrm{q}}$ is larger than $z_{\text {turb }}$ by between $20 \mathrm{~m}$ to $70 \mathrm{~m}$. One possible interpretation is that water vapor originating from the mixed layer is transferred into the EIL either by entrainment or detrainment and then subsequently transported to the low-turbulence region above the EIL by occasional turbulent eddies, as the free troposphere is not perfectly laminar, but rather substantially less turbulent. In this case, this would make $z_{\mathrm{q}}$ analogous to $z_{\text {mix }}$ from Moeng et al. (2005). If we use this interpretation, our observations generally support the 
Moeng et al. (2005) findings, with whom Kurowski et al. (2009) also agreed using a different set of large-eddy simulations.

\subsubsection{Factors controlling EIL properties}

We further attempted to evaluate what local factors and processes might control the depth, location and thermodynamic properties of the EIL by trying to correlate the EIL properties with other observed properties. We tried as many factors that we could think of, and also tried measuring the EIL in a wide variety of ways, but nothing we did led to any significant or insightful relationships. We speculate that this may occur because the EIL is not controlled locally, and instead by processes that take place over larger spatial scales (e.g. subsidence rate or horizontal advection) or by local properties whose effects must be integrated over a long time period rather than using instantaneous values of, e.g., $\Delta \theta_{\mathrm{v}}$ or $\Delta q_{\mathrm{t}}$. Stratocumulus have been shown to be strongly affected by non-local processes (Klein et al., 1995); for example, they find that low cloud amount is better correlated with sea surface and free troposphere temperatures from 24 to $30 \mathrm{hr}$ earlier than with the local values. Perhaps such non-local influences and/or processes acting over long temporal scales are also primary controls on EIL properties. To gain more insight via in situ measurements, a Lagrangian-type observational framework would be needed; the short-duration, fixed location flights from POST are not suitable for such a study.

\subsection{Entrainment efficiency}

We next examine the dependence of the entrainment efficiency $\eta$ based on Eq. (4) on various parameters. To reiterate, $\eta$ represents the fraction of the TKE produced by net cloud-top radiative cooling that is consumed by doing work against stably-stratified air, i.e. either by entrainment (pushing warm, less-dense downwards into cold air), or detrainment (pushing cold, dense air upwards into warm air). This analysis treats both cases as equivalent. Because of the aircraft sampling strategy, our actual definition of $\eta$ is:

$\eta=-\frac{\int_{z_{s, \text { min }}}^{z_{\mathrm{s} \text { max }}}\left(\left.\overline{w^{\prime} \theta_{\mathrm{v}}^{\prime}}\right|_{\ell}<0\right) d z_{\mathrm{s}}}{\int_{z_{s, \text { min }}}^{z_{\mathrm{s} \text { max }}}\left(\left.\overline{w^{\prime} \theta_{\mathrm{v}}^{\prime}}\right|_{\ell}>0\right) d z_{\mathrm{s}}} \equiv-\frac{\int-F_{\mathrm{b}}}{\int+F_{\mathrm{b}}}$

$\equiv \frac{\text { "Entrainment integral" }}{\text { "Boundary layer integral" }}$

which differs from Eq. (4) in that (i) the fluxes are filtered at a length scale $\ell \sim 100 \mathrm{~m}$ (Sect. 2.2.1) and (ii) the limits of integration are not the surface to the top of the boundary layer, but rather from $z_{\mathrm{s}, \min }$ which is a minimum shifted altitude that is approximately $100 \mathrm{~m}$ below cloud top, to $z_{\mathrm{s}, \max }$ which represents approximately the top of the region of substantial buoyancy fluxes, which one could interpret to be the top of the EIL and is typically in the range $z_{\mathrm{s}}<50 \mathrm{~m}$ (see Fig. 6). The aircraft did not frequently sample above $z_{\mathrm{s}, \max }=100 \mathrm{~m}$, but examination of each case shows that buoyancy fluxes go to nearly zero below this altitude on all days, consistent with previous studies (James, 1959). Recall (Sect. 2.2.1) that the denominator in Eq. (6) is likely underestimated to a greater degree than the numerator due to the filtering of the fluxes. As a result, filtering causes $\eta$ from Eq. (6) to likely be overestimated by (very approximately) a factor of 10 .

Our overarching goal in this section is to (i) try to elucidate the factors that are important in controlling entrainment efficiency $\eta$ (Deardorff80 suggests the variability is about one order of magnitude, c.f. Sect. 1.1) and, by extension, possibly entrainment velocity; and (ii) provide observational constraints for high-resolution models to understand in what way their simulations are and are not realistically representing entrainment. As part of this analysis, we will evaluate whether the filtered fluxes are physically meaningful and useful for understanding entrainment.

\subsubsection{Calculating entrainment efficiency $\eta$}

In order to calculate $\eta$, we need to compute both the numerator and denominator in Eq. (6), which we have denoted as $\int-F_{\mathrm{b}}$ (or the "entrainment integral") and $\int+F_{\mathrm{b}}$ (the "boundary layer integral"), respectively, for convenience. We start with the total buoyancy flux profile (Figs. 2 to 5), which is constructed by computing the mean buoyancy flux at each $10-\mathrm{m} z_{\mathrm{s}}$ bin (Sect. 2.2.1) using all sawtooth-leg data from each flight. Next, the region of the buoyancy flux profile where the values are negative and substantially different from zero, corresponding to the numerator of Eq. (6), is selected visually, and the flux values are integrated. We then do the same for the region with positive values to construct the denominator of Eq. (6). Both of these regions are shaded in Figs. 2 to 5 to illustrate the method. This method results in a single value of $\eta$ for each flight.

From the profiles in Figs. 2 to 5, it is clear that the buoyancy flux does not reach zero for $z_{\mathrm{s}}=-100 \mathrm{~m}$, which reveals another limitation of these data: there is clearly substantial (positive) buoyancy flux below our lowest sampling level and thus our denominator is underestimated due to our limited sampling altitudes. Note that the numerator does not experience the same problem, as for all flights we do sample the full range of altitudes with net negative buoyancy flux. Note that this underestimation combines with the effects of filtering the fluxes for small scales, which also disproportionately causes the denominator to be underestimated. For these two reasons, then, the efficiencies computed here are likely to be overestimated, and indeed we find days where our computed efficiency can be greater than unity, which is, strictly speaking possible (c.f. the Lilly (1968) maximum entrainment case) but is neither likely nor in line with other studies which suggest values in the range of 0.01 to 0.1 (Deardorff80).

The calculated values of $\eta$ across all sixteen flights vary widely, from $1 \times 10^{-3}$ to $3 \times 10^{1}$, spanning more than four orders of magnitude. However, upon examining the buoyancy 


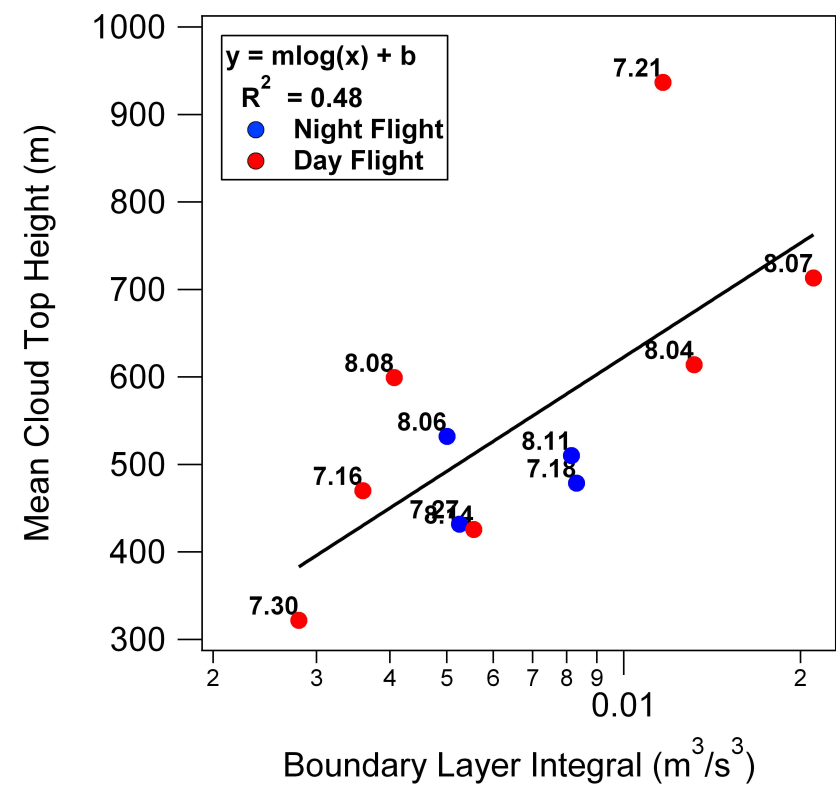

Fig. 7. Scatter plot of the boundary layer integral, $\int+F_{\mathrm{b}}$, versus mean cloud top height. Each point is the average value for the flight, with the corresponding date beside each point, and color denoting day and night flights.

flux profiles, all of the extreme (both very small and very large) values of $\eta$ occur when only one 10-m altitude bin contributed to either the numerator ( 3 cases) or denominator (2 cases), and this single value was in each case quite small, not too far outside the range of the estimated noise, which gives us little confidence in these values. We have eliminated these cases from further examination due to the potential for large uncertainty in these values and hence in the subsequently derived $\eta$ values. By requiring both $\int-F_{\mathrm{b}}$ and $\int+F_{\mathrm{b}}$ to have contributions from at least two $10-\mathrm{m}$ bins, the range of $\eta$ values narrows to between 0.03 and 1 (to one one significant figure). Even after removing the more uncertain estimates of $\eta$, the span of a factor of 30 suggests that $\eta$ is not constant, as assumed by KS78. The span of values is reasonably compatible with that derived from LES by Deardorff80, where they found values spanning a factor of 10 , between 0.01 to 0.1 .

Some of this variability may be due to filtering, which could introduce variability (particularly in $\int+F_{\mathrm{b}}$ ) if the size of the largest eddies relevant to either buoyant production/consumption of TKE changes. We test this idea by plotting $\int+F_{\mathrm{b}}$ versus mean cloud top height for all days (Fig. 7). There is the possibility that, as the eddies get larger, our filtered flux captures a smaller fraction of the true vertical flux, and we would find that $\int+F_{\mathrm{b}}$ is negatively correlated with cloud top height. We find instead that as the eddies become larger, our filtered flux also increases, which (all else being equal) is consistent with classic turbulence theory and therefore suggestive that the filtered fluxes can be useful. More results presented next will also contribute to our understanding of the utility and limitations of the filtered flux observations.

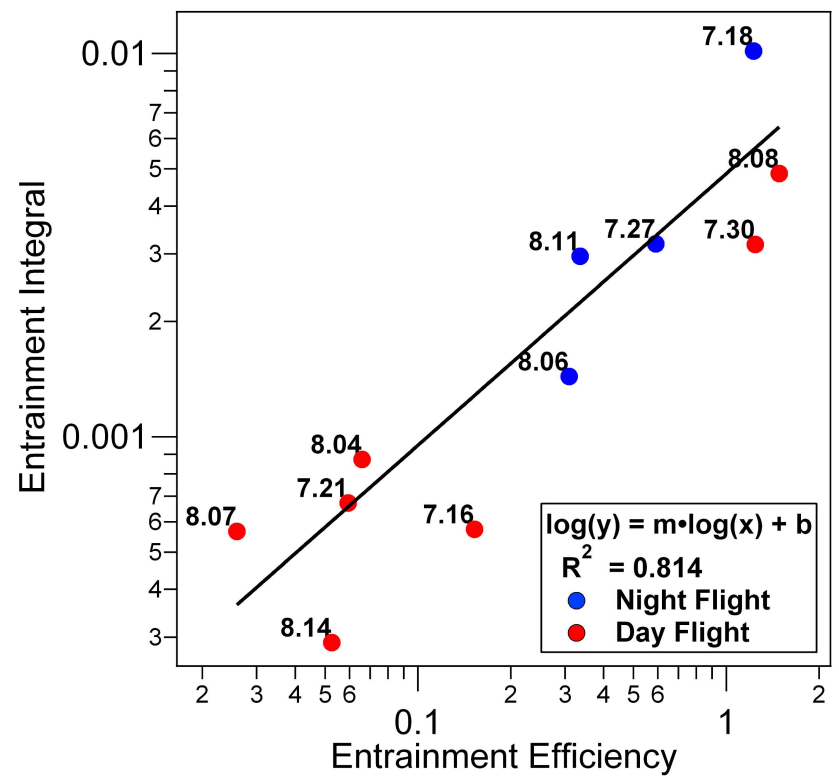

Fig. 8. Scatter plot of the entrainment efficiency $\eta$ versus the entrainment integral (i.e. $\int-F_{\mathrm{b}}$ from Eq. 6). Each point is the average value for the flight, with the corresponding date beside each point, and color denoting day and night flights.

\subsubsection{Entrainment efficiency dependence on buoyancy flux integrals}

We now seek to understand what parameters may be controlling the entrainment efficiency $\eta$. Note that Table 2 summarizes the correlations among different parameters discussed below. First, we examine the contribution of the two terms in the terms in the $\eta$ equation, $\int-F_{\mathrm{b}}$ and $\int+F_{\mathrm{b}}$, to $\eta$ (Figs. 8 and 9). Not surprisingly, both correlate quite well with $\eta$ with $R^{2}$ values of 0.8 and 0.5 , respectively, but the correlation with $\int-F_{\mathrm{b}}$ is larger, suggesting that this term is potentially more variable than $\int+F_{\mathrm{b}}{ }^{2}$. Interestingly, there is no correlation (data not shown) between $\int-F_{\mathrm{b}}$ and $\int+F_{\mathrm{b}}$. This is important because it implies that $\eta$ is computed from two independent quantities, and can not be predicted by either one alone. Also, since $\int+F_{\mathrm{b}}$ is intended to measure the primary source of boundary layer TKE, the fact that the rate of TKE consumption by entrainment does not correlate with the production of TKE is not necessarily expected. We interpret this to mean that while BL turbulence is necessary for entrainment, other factors are more important in governing the fraction of this energy that is used for entrainment, i.e. in governing $\int-F_{\mathrm{b}}$.

\footnotetext{
${ }^{2}$ For all of the correlations described in the remainder of this section, a log scale is used for those quantities that varied widely $(\eta$, $\int+F_{\mathrm{b}}$, and $\int-F_{\mathrm{b}}$ ), while a linear scale is used for others, as their range was more limited. The choice of log versus linear scale, therefore, depended on convenience and has no theoretical rationale.
} 


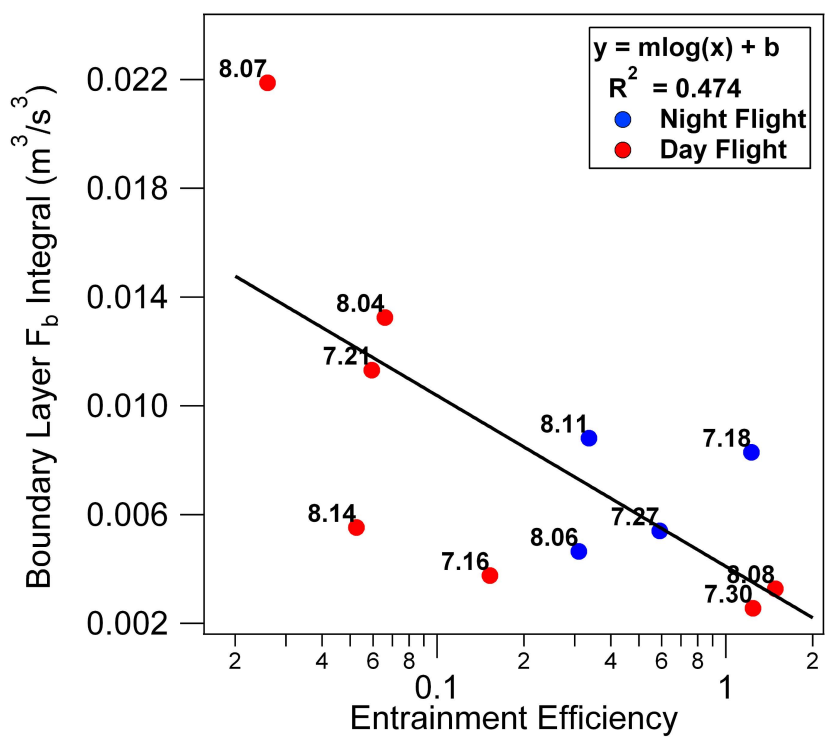

Fig. 9. Scatter plot of the entrainment efficiency $\eta$ versus the boundary layer integral (i.e. $\int+F_{\mathrm{b}}$ from Eq. 6 ). Each point is the average value for the flight, with the corresponding date beside each point, and color denoting day and night flights.

\subsubsection{Entrainment efficiency dependence on stratification}

Many entrainment parameterizations seek to relate the thermodynamic properties of the cloud top region to the entrainment velocity $w_{\mathrm{e}}$. The most obvious property relevant to $w_{\mathrm{e}}$ is degree to which the EIL is stably stratified, which can be measured either as a density jump $\left(\Delta \theta_{\mathrm{v}}\right)$ or a density gradient $\left(d \theta_{\mathrm{v}} / d z\right)$. Here, we choose to use the latter because determining the altitudes across which a jump is computed is often ambiguous. Most of the time the ambiguity comes from defining the top of the EIL (see Figs. 2 to 5 for sample $\theta_{\mathrm{v}}$ profiles). Figure 10 shows a plot of $\eta$ versus maximum $\Delta \theta_{\mathrm{v}} / \Delta z$, where the latter is the maximum gradient as computed from the $10 \mathrm{~m}$ altitude bins, and occurs at a shifted altitude of $z_{\mathrm{s}}=0$ to $20 \mathrm{~m}$ (Fig. 6). We find that $\eta$ is negatively correlated with maximum $d \theta_{\mathrm{v}} / d z\left(R^{2}=0.5\right)$. We interpret this as stronger stratification of the EIL $\left(d \theta_{\mathrm{v}} / d z\right.$ very large) results in a much smaller fraction of the boundary layer TKE that is consumed by entrainment. This correlation is not trivial, since it is plausible that the same fraction of boundary layer turbulence is always consumed by entrainment (as is assumed by KS78). This negative correlation, however, suggests that, as stability increases, a smaller fraction of the TKE generated in the boundary layer is converted into entrainment or detrainment work and a larger fraction of the TKE goes into driving turbulent motions in the boundary layer. We suggest that this qualitative relationship could be used as an important test of models simulating entrainment in the STBL. Interestingly, Sun and Wang (2008) interpreted previous experimental results and found a similar result between

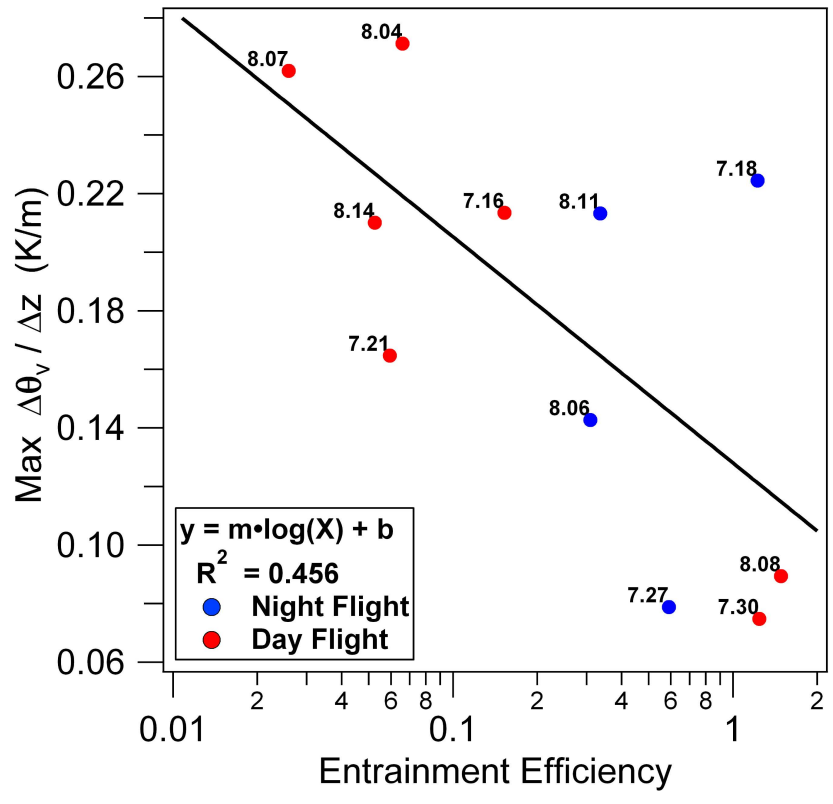

Fig. 10. Scatter plot of the entrainment efficiency $\eta$ versus the maximum $\theta_{\mathrm{v}}$ gradient, which is a measure of the stable stratification of the air in the cloud top region. Each point is the average value for the flight, with the corresponding date beside each point, and color denoting day and night flights.

the analogous quantity in dry convective boundary layers, the entrainment flux ratio, and stratification.

We also examined the relevance of the maximum moisture gradient $d q_{\mathrm{t}} / d z$ and find no correlations between this quantity and any of the other entrainment parameters. This suggests that the moisture contrast is more strongly controlled by other factors, such as advection. This makes sense since the moisture is not a first-order term in controlling properties that turbulent entrainment is likely to be sensitive to, such as air density or TKE.

To better understand how entrainment may be controlled by the maximum density gradient, $d \theta_{\mathrm{v}} /\left.d z\right|_{\max }$ is plotted versus $\int-F_{\mathrm{b}}$ and $\int+F_{\mathrm{b}}$ (Figs. 11 and 12 ), yielding $R^{2}$ values of 0.2 (negatively correlated) and 0.6 (positively correlated), respectively. However, if one point (7/18) is removed as an outlier from the $\int-F_{\mathrm{b}}$ plot, $R^{2}$ increases from 0.2 to 0.5 . While there's no clear physical justification for doing so, considering this value as an outlier and keeping all eleven other points does drastically improve $R^{2}$. If we accept this outlier, then the data suggests that $d \theta_{\mathrm{v}} /\left.d z\right|_{\max }$ is important in controlling both $\int-F_{\mathrm{b}}$ and $\int+F_{\mathrm{b}}$, each of which in turn directly impacts $\eta$. But given that $\int-F_{\mathrm{b}}$ and $\int+F_{\mathrm{b}}$ are themselves uncorrelated, stratification can not be the only important factor.

The negative correlation between $d \theta_{\mathrm{v}} /\left.d z\right|_{\max }$ and $\int-F_{\mathrm{b}}$ could be explained by the idea that entrainment is inhibited by stronger stratification in the EIL region. A positive 


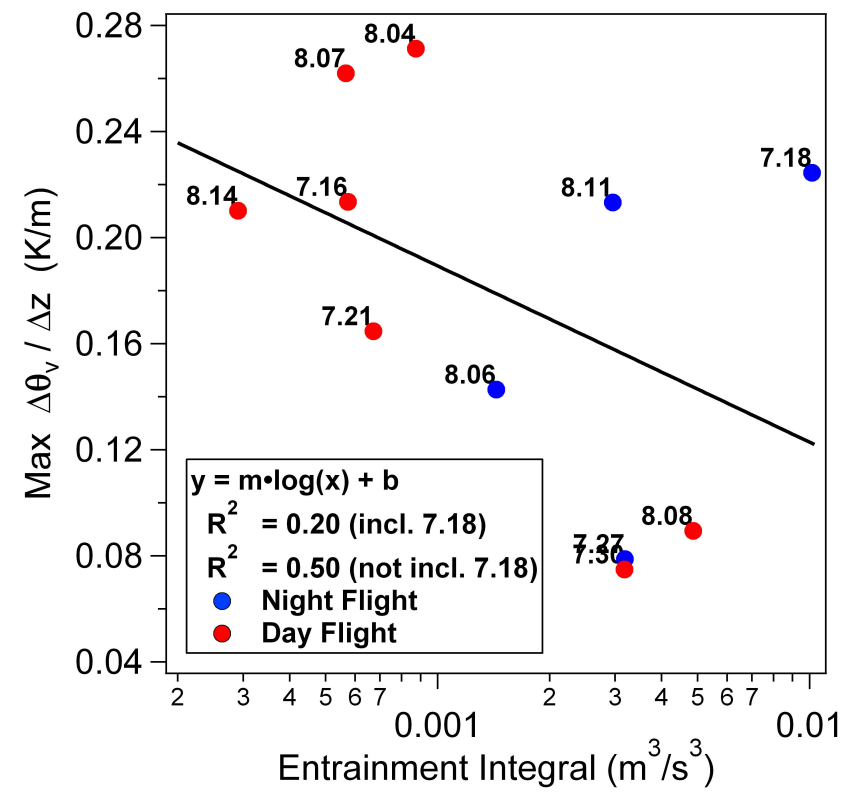

Fig. 11. Scatter plot of the entrainment integral (i.e. $\int-F_{\mathrm{b}}$ from Eq. 6) versus the maximum $\theta_{\mathrm{v}}$ gradient, which is a measure of the stable stratification of the air in the cloud top region. Each point is the average value for the flight, with the corresponding date beside each point, and color denoting day and night flights.

correlation between stability $\left(d \theta_{\mathrm{v}} /\left.d z\right|_{\max }\right)$ and $\int+F_{\mathrm{b}}$ seems harder to explain. One simple explanation that appears inconsistent with the data is that inhibiting the consumption of TKE through entrainment (i.e. reducing $\int-F_{\mathrm{b}}$ ) means that more energy is available to drive circulations in the boundary layer. However, this would imply a negative correlation between $\int-F_{\mathrm{b}}$ and $\int+F_{\mathrm{b}}$, which are instead uncorrelated (data not shown) and thus this explanation does not seem to fit the observations. An alternate explanation starts with the observed starts with the observed correlation $\left(R^{2}=0.7\right.$; data not shown) between $d \theta_{\mathrm{v}} /\left.d z\right|_{\max }$ and the magnitude of the moisture gradient. A drier free troposphere exhibits decreased downwelling IR, thus increasing net cloud-top IR cooling, which would increase positive buoyancy production $\int+F_{\mathrm{b}}$. The observations reveal a strong correlation ( $R^{2}=0.6$; data not shown) between the moisture gradient and $\int+F_{\mathrm{b}}$ which is consistent with this idea.

\subsubsection{Entrainment efficiency dependence on turbulence}

We next examine the role of turbulence, as measured by the vertical component of the TKE, $\overline{\left(w^{\prime}\right)^{2}}$. We compute two measures of turbulence: (i) mean $\overline{\left(w^{\prime}\right)^{2}}$ for the entire region of the boundary layer that was consistently sampled, $z_{\mathrm{s}}=-100 \mathrm{~m}$ to $0 \mathrm{~m}$, denoted $\overline{\left(w^{\prime}\right)_{\mathrm{BL}}^{2}}$; and (ii) mean $\overline{\left(w^{\prime}\right)^{2}}$ for the cloud top region, $z_{\mathrm{s}}$ from $-20 \mathrm{~m}$ to $0 \mathrm{~m}$, denoted $\overline{\left(w^{\prime}\right)_{\mathrm{CT}}^{2}}$. We note that these two quantities are strongly correlated $\left(R^{2}=0.7\right.$; data not shown) which is expected since the latter is a subset of

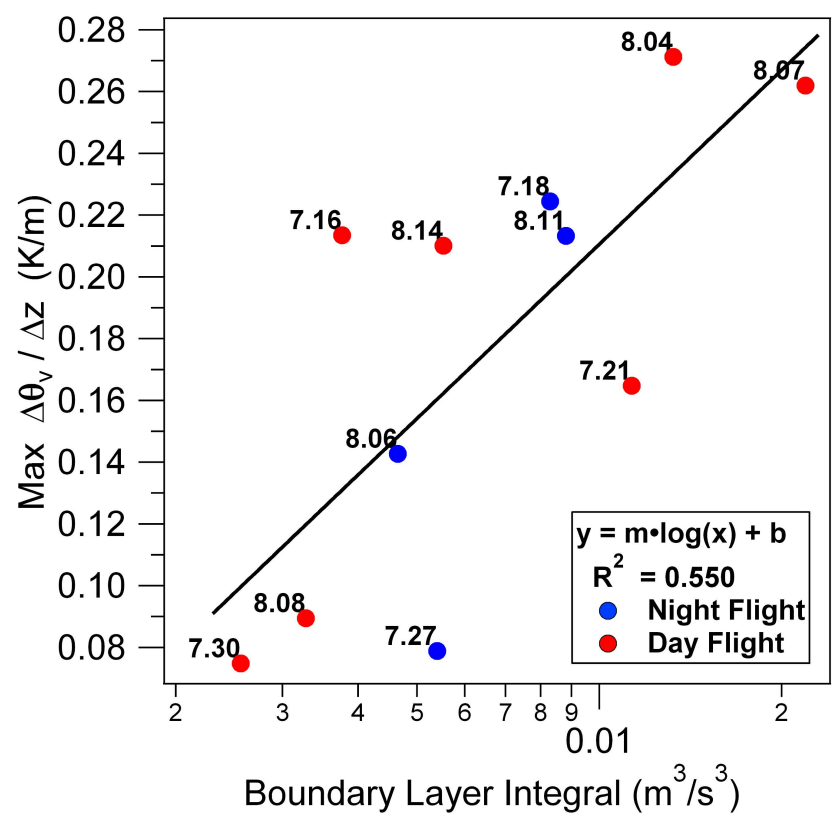

Fig. 12. Scatter plot of the boundary layer integral (i.e. $\int+F_{\mathrm{b}}$ from Eq. 6) versus the maximum $\theta_{\mathrm{v}}$ gradient, which is a measure of the stable stratification of the air in the cloud top region. Each point is the average value for the flight, with the corresponding date beside each point, and color denoting day and night flights.

the former. When compared with $\eta$, we find no correlation between $\eta$ and $\overline{\left(w^{\prime}\right)_{\mathrm{BL}}^{2}}$ (not shown), and a very weak correla-

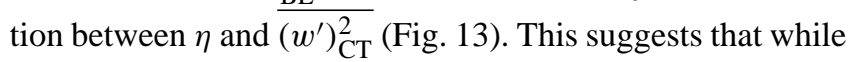
entrainment by definition requires turbulence, the amount of TKE does not appear to control the $\eta$. In contrast, the correlation between $\eta$ and $d \theta_{\mathrm{v}} /\left.d z\right|_{\max }$ is fairly strong (Fig. 10), and thus the thermodynamic properties of the interfacial region do appear to matter more so than the dynamic properties. That turbulence does not appear to be related to $\eta$ and stability does is particularly interesting because both $w^{\prime}$ and $\theta_{\mathrm{v}}^{\prime}$ are needed to compute buoyancy fluxes, and hence in calculating $\eta$. This lack of correlation is another potentially useful test of STBL entrainment simulations.

Because $d \theta_{\mathrm{v}} /\left.d z\right|_{\max }$ is correlated with $\eta$, we examine whether cloud-top turbulence relates to stratification. These quantities, $d \theta_{\mathrm{v}} /\left.d z\right|_{\max }$ and $\overline{\left(w^{\prime}\right)_{\mathrm{CT}}^{2}}$, could be correlated if the work required to entrain stably stratified air comes directly from cloud top turbulence; if so, then a negative correlation would be expected. However, we find no correlation between these quantities, nor of $d \theta_{\mathrm{v}} /\left.d z\right|_{\max }$ with $\overline{\left(w^{\prime}\right)_{\mathrm{BL}}^{2}}$.

\subsubsection{Entrainment efficiency dependence on CTEI}

Cloud top entrainment instability (CTEI) has been hypothesized to play a role in entrainment and subsequent break up of stratocumulus (e.g., Deardorff, 1980; Randall, 1980). Briefly, the concept posits that when certain mixtures of boundary 


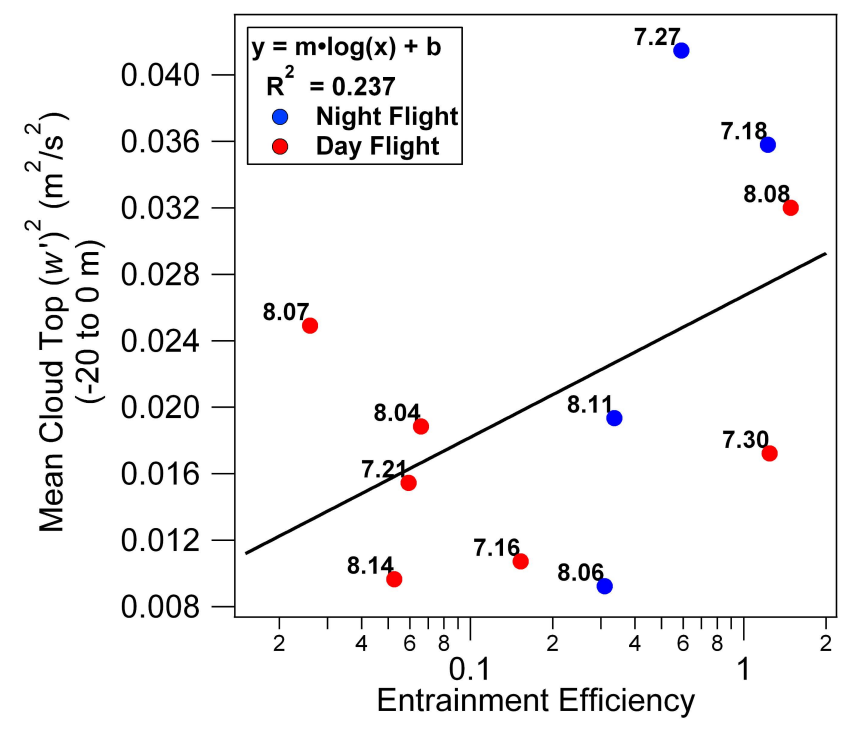

Fig. 13. Scatter plot of the entrainment efficiency $\eta$ versus the vertical component of TKE $\overline{\left(w^{\prime}\right)^{2}}$ near cloud top (from $z_{\mathrm{s}}=0 \mathrm{~m}$ to $-20 \mathrm{~m}$ ). Each point is the average value for the flight, with the corresponding date beside each point, and color denoting day and night flights.

layer and free tropospheric air are denser than the boundary layer air, the mixtures will subsequently sink and thereby lead to entrainment of free tropospheric air; the TKE thus generated will also enhance entrainment, leading to a positive feedback. We compute the Deardorff-Randall criterion $\kappa$ as (Stevens et al., 2003):

$\kappa=1+\frac{\Delta T c_{p}-L \Delta q_{1}}{L \Delta q_{\mathrm{t}}}$

where $T$ is temperature, $c_{p}$ is the heat capacity of air, and $L$ is latent heat of vaporization. All $\Delta x$ are calculated as $x_{\mathrm{FT}}-x_{\mathrm{BL}}$. Theory predicts that if $\kappa>\kappa^{*} \simeq 0.23$ then buoyancy reversal can occur and lead to strong entrainment. Figure 14 plots $\eta$ versus $\kappa$ to see if the latter appears to influence the former. There is no correlation, from which we conclude that buoyancy reversal is not a relevant factor in determing $\eta$. This result is consistent with other previous studies which find that stratocumulus can persist under conditions where the CTEI condition is met and thus is predicted to break up (Siems et al., 1990; Stevens et al., 2003; Faloona et al., 2005). Yamaguchi and Randall (2008) argue that this feedback occurs but is weak and thus is not a sufficient condition for stratocumulus break up.

\section{Conclusions}

In this study, aircraft observations from POST are used to characterize the entrainment interface layer (EIL) and study parameters related to entrainment. The observations obtained

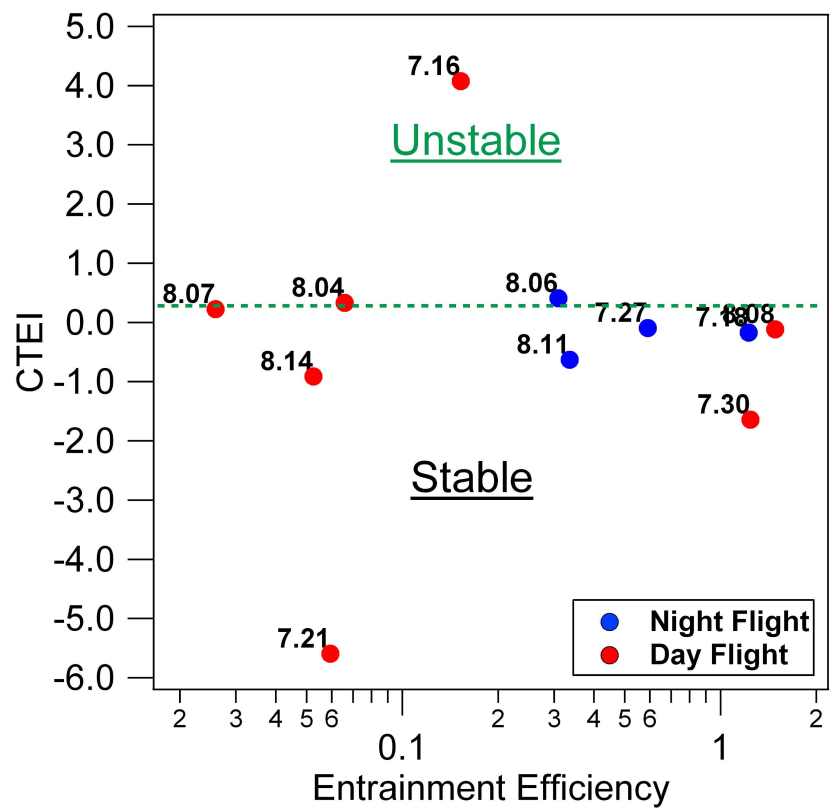

Fig. 14. Scatter plot of the entrainment efficiency $\eta$ versus the CTEI Deardorff-Randall criterion $\kappa$ (see Eq. 6). Each point is the average value for the flight, with the corresponding date beside each point, and color denoting day and night flights. The dotted line denotes the $\kappa^{*}=0.23$ threshold.

from the sawtooth flight pattern that was primarily utilized during this project are shifted to a cloud-top referenced vertical coordinate, and then binned at $10 \mathrm{~m}$ intervals. This study uses mean profiles from each flight for analysis.

\subsection{EIL structure}

During POST, we find that the vertical location and thickness of the EIL changes depending on how it is defined. We chose to define the EIL using three parameters: turbulence, buoyancy and moisture. We found that defining the EIL using either turbulence or buoyancy are fairly consistent with each other and give EIL thicknesses on the order of $50 \mathrm{~m}$, although the turbulence EIL appears to lie about $10 \mathrm{~m}$ below the buoyancy EIL. The bottom of the EIL is almost always below cloud top, but more of the EIL resides above cloud top. The maximum gradient in turbulence is usually very close to cloud top (within $10 \mathrm{~m}$ ), with a majority of the cases locating it right at cloud top. The maximum gradient in buoyancy tends to be slightly above cloud top (by 5 to $10 \mathrm{~m}$ ), consistent with the shift in the EIL. Defining the EIL by moisture leads to great ambiguity and inconsistency in the location and vertical extent of the EIL. Combining these results with the buoyancy flux profiles shows that the active region for net negative buoyancy production coincides with the EIL. This suggests an inter-relationship, also described by Lewellen and Lewellen (1998), where the EIL gradients affect entrainment, while the entrainment fluxes affect the 
gradients, which motivates further and deeper understanding of the coupling between the EIL and entrainment.

We use the results from the POST project to test the findings of Moeng et al. (2005), who find that the top of the boundary layer differs depending on the definition. While we can not observe exactly the same parameters that they analyze using LES, our results do appear to be consistent with their results, where cloud top is below the maximum gradient interface, which is in turn is below the top where passive tracers can be transported.

\subsection{Entrainment}

The entrainment velocity $w_{\mathrm{e}}$ of stratocumulus-topped boundary layers is believed to depend on a number of parameters, among them (i) the strength of stratification at cloud top; (ii) the strength of the turbulence either in the boundary layer or near the interface; and (iii) one or more terms representing effects of evaporation. Additionally, most parameterizations of $w_{\mathrm{e}}$ require knowledge of one dimensionless number (or more) that is typically found by observation (e.g. $a$ in Eq. 1). In this study, we utilize the dimensionless number $\eta$ based on the KS78 parameterization which we term the entrainment efficiency. This entrainment efficiency has been hypothesized to be a constant (e.g. KS78), but a modeling study (Deardorff80) suggests that $\eta$ ranges by almost a factor of 10 .

The results of this study should be interpreted with the appropriate caveats. Most importantly, all the fluxes computed in this study are filtered for spatial scales less than $100 \mathrm{~m}$. The sawtooth flight pattern that permits good statistical sampling of the vertical structure of the EIL region also precludes accurate estimation of full (i.e. unfiltered) fluxes. One of our goals was to provide novel and useful constraints for models, in particular high-resolution large-eddy simulations that are often used to study entrainment. In order for this study to serve this purpose, model results would need to be filtered in a similar way in order to be compared with the observations. Although it does require extra processing of model output to do so, it should be a relatively straightforward process. Whether our results apply to unfiltered fluxes is not known, but this is a question that LES may help answer in the future. If these models replicate the constraints described by this study, then we would have much more confidence in their ability to explain, for example, the factors that $\operatorname{control} \eta$.

The absolute values of any turbulent fluxes, and therefore quantities that depend on them (in particular $\eta$ ) must be viewed as being biased due to the spatial filtering. Because of the differences in characteristic eddy size between the boundary layer (hundreds to thousands of meters) and those responsible for entrainment (likely tens of meters or less), the filtering does not impact all variables in the same way. We argue above (Sect. 2.2.1) that $\eta$ is overestimated due to the filtering by approximately a factor of 10 , but this is unlikely to be constant.
Given these caveats, we find that in the coastal stratocumulus sampled during POST, $\eta$ varies widely (we estimate 1.5 orders of magnitude) which is consistent with but larger than Deardorff80 (one order of magnitude) and is inconsistent with KS78 which assumes a constant. Our results further suggest that $\eta$ :

1. does depend on the stratification strength, which we measure using maximum $d \theta_{\mathrm{v}} / d z$. Qualitatively similar results have been suggested by studies in dry convective boundary layers (e.g., Deardorff et al., 1980; Sun and Wang, 2008).

2. does not depend directly on the strength of turbulence either in the boundary layer or at the interface as measured by $\overline{\left(w^{\prime}\right)^{2}}$.

3. does not depend on the CTEI criterion for buoyancy reversal (although this does not exclude all evaporation processes from being important).

Whether these observational constraints are currently met by models such as high resolution LES remains an open question. We speculate that the model representation of the subgrid scale fluxes may play an important role in such an exercise.

\section{Appendix A}

\section{Nomenclature and abbreviations}

EIL entrainment interface layer

$h \quad$ cloud top height

KS78 Kraus and Schaller (1978)

NT86 Nicholls and Turton (1986)

Ri Richardson number

$q_{\mathrm{v}} \quad$ specific water vapor mixing ratio

$q_{1} \quad$ specific liquid water mixing ratio

$q_{\mathrm{t}} \quad$ specific total water mixing ratio $=q_{\mathrm{v}}+q_{1}$

$w_{\mathrm{e}} \quad$ entrainment velocity

$w_{*} \quad$ convective velocity scale

$\overline{\left(w^{\prime}\right)^{2}} \quad$ vertical component of TKE

$z_{\mathrm{s}} \quad$ shifted altitude coordinate; $z_{\mathrm{s}}=0 \mathrm{~m}$ is the cloud top as defined by liquid water

$z_{\theta v} \quad$ EIL top defined by $\theta_{\mathrm{v}}$ (from this study)

$z_{\mathrm{q}} \quad$ EIL top defined by total water mixing ratio (from this study) 


$\begin{array}{ll}z_{\text {turb }} & \text { EIL top defined by } \overline{\left(w^{\prime}\right)^{2}} \text { (from this study) } \\ z_{\text {mix }} & \begin{array}{l}\text { EIL top defined by the maximum altitude to } \\ \text { which tracers are transported (from Moeng et } \\ \text { al., 2005) }\end{array} \\ z_{\text {mgd }} & \begin{array}{l}\text { EIL top defined by the maximum gradient in EIL } \\ \text { properties (from Moeng et al., 2005) }\end{array} \\ z_{\text {lwc }} & \begin{array}{l}\text { EIL top defined by cloud top (from Moeng et al., } \\ \text { 2005) }\end{array} \\ \theta_{\mathrm{v}} & \text { entrainment efficiency } \\ \int-F_{\mathrm{b}} & \begin{array}{l}\text { sink of TKE by turbulent vertical buoyancy } \\ \text { transport (primarily by entrainment and/or de- } \\ \text { trainment) within the sampled region; some- } \\ \text { times referred to here as the "entrainment inte- } \\ \text { gral" }\end{array}\end{array}$

$\int+F_{\mathrm{b}} \quad$ source of TKE by buoyancy production (primarily cloud top radiative cooling) within the sampled region; sometimes referred to here as the "boundary layer integral"

Acknowledgements. J. Carman, D. Rossiter and P. Chuang thank the Physical Meteorology program of the National Science Foundation (\#0736046) for their support and encouragement for this project. D. Khelif also thanks NSF/Physical Meteorology for supporting his effort. The authors are very grateful to the CIRPAS Twin Otter pilots and technical staff for their hard work to ensure that the flights were successful. We also thank the rest of the POST science team, especially Herman Gerber, for their contributions and discussions before, during and after the field campaign. Lastly, we thank Rob Wood and Jonathan Petters for helpful discussions.

Edited by: A. Nenes

\section{References}

Bachalo, W. D.: Method for measuring the size and velocity of spheres by dual-beam light-scatter interferometry, Appl. Opt., 19, 363-370, 1980.

Bachalo, W. D. and Houser, M. J.: Phase doppler spray analyzer for simultaneous measurements of drop size and velocity distributions, Opt. Eng., 23, 583-590, 1984.

Ball, F. K.: Control of inversion height by surface heating, Q. J. Roy. Meteor. Soc., 86, 483-494, doi:10.1002/qj.49708637005, 1960.

Betts, A. K., and Ball, J. H.: Budget analysis of FIFE-1987 sonde data, J. Geophys. Res., 99, 3655-3666, doi:10.1029/93JD02739, 1994.

Bretherton, C. S., Blossey, P. N., and Uchida, J.: Cloud droplet sedimentation, entrainment efficiency, and subtropical stratocumulus albedo, Geophys. Res. Lett., 34, L03813, doi:10.1029/2006GL027648, 2007.
Caughey, S. J., Crease, B. A., and Roach, W. T.: A fieldstudy of nocturnal stratocumulus .2. turbulence structure and entrainment, Q. J. Roy. Meteor. Soc., 108, 125-144, doi:10.1256/smsqj.45507, 1982.

Chuang, P. Y., Saw, E. W., Small, J. D., Shaw, R. A., Sipperley, C. M., Payne, G. A., and Bachalo, W. D.: Airborne phase Doppler interferometry for cloud microphysical measurements, Aerosol Sci. Tech., 42, 685-703, doi:10.1080/02786820802232956, 2008.

Deardorff, J. W.: Stratocumulus-capped mixed layers derived from a 3-dimensional model, Bound.-Lay. Meteor., 18, 495-527, 1980a.

Deardorff, J. W.: Cloud top entrainment instability, J. Atmos. Sci., 37, 131-147, 1980b.

Deardorff, J. W., Willis, G., and Stockton, B.: Laboratory studies of the entrainment zone in a convectively mixed layer, J. Fluid Mech., 100, 41-64, 1980.

Faloona, I., Lenschow, D. H., Campos, T., Stevens, B., van Zanten, M., Blomquist, B., Thornton, D., Bandy, A., and Gerber, H.: Observations of entrainment in eastern Pacific marine stratocumulus using three conserved scalars, J. Atmos. Sci., 62, 3268-3285, 2005.

Gerber, H., Arends, B. G., and Ackerman, A. S.: New microphysics sensor for aircraft use, Atmos. Res., 31, 235-252, 1994.

Gerber, H., Frick, G., Malinowski, S. P., Brenguier, J. L. and Burnet, F.: Holes and entrainment in stratocumulus, J. Atmos. Sci., 62, 443-459, 2005.

Glickman, T. S.: Glossary of Meteorology, available at: http: //amsglossary.allenpress.com/glossary/search?id=entrainment1, Am. Meteorol. Soc., 2000.

Haman, K. E., Malinowski, S. P., Kurowski, M. J., Gerber, H. and Brenguier, J. L.: Small scale mixing processes at the top of a marine stratocumulus - a case study, Q. J. Roy. Meteor. Soc., 133, 213-226, doi:10.1002/qj.5, 2007.

James, D. G.: Observations from aircraft of temperatures and humidities near stratocumulus clouds, Q. J. Roy. Meteor. Soc., 85, 120-130, 1959.

Klein, S. A., Hartmann, D. L. and Norris, J. R.: On the relationships among low-cloud structure, sea-surface temperature, and atmospheric circulation in the summertime northeast Pacific, J. Climate, 8, 1140-1155, 1995.

Kraus, H. and Schaller, E.: Note on closure in Lilly-type inversion models, Tellus, 30, 284-288, 1978.

Kurowski, M. J., Malinowski, S. P. and Grabowski, W. W.: A numerical investigation of entrainment and transport within a stratocumulus-topped boundary layer, Q. J. Roy. Meteor. Soc., 135, 77-92, doi:10.1002/qj.354, 2009.

Lenschow, D. H., Zhou, M. Y., Zeng, X. B., Chen, L. S., and $\mathrm{Xu}, \mathrm{X}$. D.: Measurements of fine-scale structure at the top of marine stratocumulus, Bound.-Lay. Meteor., 97, 331-357, doi:10.1023/A:1002780019748, 2000.

Lewellen, D. and Lewellen, W.: Large-eddy boundary layer entrainment, J. Atmos. Sci., 55, 2645-2665, 1998.

Lilly, D. K.: Models of cloud-topped mixed layers under a strong inversion, Q. J. Roy. Meteor. Soc., 94, 292-309, doi:10.1002/qj.49709440106, 1968.

Moeng, C. H., Stevens, B., and Sullivan, P. P.: Where is the interface of the stratocumulus-topped PBL?, J. Atmos. Sci., 62, 26262631, 2005. 
Nicholls, S. and Turton, J. D.: An observational study of the structure of stratiform cloud sheets.2. entrainment, Q. J. Roy. Meteor. Soc., 112, 461-480, 1986.

Randall, D. A.: Conditional instability of the 1st kind upside-down, J. Atmos. Sci., 37, 125-130, 1980.

Sankar, S. V., Weber, B. J., Kamemoto, D. Y., and Bachalo, W. D.: Sizing fine particles with the phase-Doppler interferometric technique, Appl. Opt., 30, 4914-4920, 1991.

Siems, S. T., Bretherton, C. S., Baker, M. B., Shy, S. S., and Breidenthal, R. E.: Buoyancy reversal and cloud-top entrainment instability, Q. J. Roy. Meteor. Soc., 116, 705-739, doi:10.1002/qj.49711649309, 1990.

Stevens, B. and Brenguier, J. L.: Clouds in the Perturbed Climate System: Their Relationship to Energy Balance, Atmospheric Dynamics, and Precipitation (Strü ngmann Forum Reports), Chapter 8: Cloud-controlling Factors: Low Clouds, 173-196, MIT Press, 2009.

Stevens, B., Lenschow, D. H., Faloona, I., Moeng, C. H., Lilly, D. K., Blomquist, B., Vali, G., Bandy, A., Campos, T., Gerber, H., Haimov, S., Morley, B., and Thornton, D.,: On entrainment rates in nocturnal marine stratocumulus, Q. J. Roy. Meteor. Soc., 129, 3469-3493, doi:10.1256/qj.02.202, 2003.
Stevens, B., Moeng, C. H., Ackerman, A. S., Bretherton, C. S., Chlond, A., De Roode, S., Edwards, J., Golaz, J. C., Jiang, H. L., Khairoutdinov, M., Kirkpatrick, M. P., Lewellen, D. C., Lock, A., Muller, F., Stevens, D. E., Whelan, E., and Zhu, P.: Evaluation of large-eddy simulations via observations of nocturnal marine stratocumulus, Mon. Weather Rev., 133, 1443-1462, 2005.

Stull, R. B.: An Introduction to Boundary Layer Meteorology, Springer, 1988.

Sun, J. N., and Wang, Y.: Effect of the entrainment flux ratio on the relationship between entrainment rate and convective Richardson number, Bound.-Lay. Meteor., 126, 237-247, doi:10.1007/s10546-007-9231-4, 2008.

Wang, Q. and Albrecht, B. A.: Observations of cloud-top entrainment in marine stratocumulus clouds, J. Atmos. Sci., 51, 1530 1547, 1994.

Wendisch, M., Garrett, T. J., and Strapp, J. W.: Wind tunnel tests of the airborne PVM-100A response to large droplets, J. Atmos. Oceanic Tech., 19, 1577-1584, 2002.

Wyngaard, J. C.: Turbulence in the Atmosphere, Cambridge University Press, 259-262, 2010.

Yamaguchi, T. and Randall, D. A.: Large-eddy simulation of evaporatively driven entrainment in cloud-topped mixed layers, J. Atmos. Sci., 65, 1481-1504, doi:10.1175/2007JAS2438.1, 2008. 